\title{
Review \\ Radiofrequency Electromagnetic Field Exposure and Apoptosis: A Scoping Review of In Vitro Studies on Mammalian Cells
}

\author{
Stefania Romeo ${ }^{1}(0)$, Olga Zeni $\left.{ }^{1, *} \mathbb{(}\right)$, Maria Rosaria Scarfi ${ }^{1}\left(\mathbb{D}\right.$, Loredana Poeta $^{1}{ }^{1}$, Maria Brigida Lioi ${ }^{1,2}$ \\ and Anna Sannino ${ }^{1}$ (i) \\ 1 CNR, Institute for Electromagnetic Sensing of the Environment (IREA) via Diocleziano 328, \\ 80124 Napoli, Italy; romeo.s@irea.cnr.it (S.R.); scarfi.mr@irea.cnr.it (M.R.S.); poeta.1@irea.cnr.it (L.P.); \\ maria.lioi@unibas.it (M.B.L.); sannino.a@irea.cnr.it (A.S.) \\ 2 Department of Science, University of Basilicata, Viale dell'Ateneo Lucano, 85100 Potenza, Italy \\ * Correspondence: zeni.o@irea.cnr.it; Tel.: +39-081-7620657
}

check for

updates

Citation: Romeo, S.; Zeni, O.; Scarfi, M.R.; Poeta, L.; Lioi, M.B.; Sannino, A. Radiofrequency Electromagnetic Field Exposure and Apoptosis: A Scoping Review of In Vitro Studies on Mammalian Cells. Int. J. Mol. Sci. 2022, 23, 2322. https://doi.org/ $10.3390 /$ ijms 23042322

Academic Editor: Yoshiro

Kobayashi

Received: 4 January 2022

Accepted: 16 February 2022

Published: 19 February 2022

Publisher's Note: MDPI stays neutral with regard to jurisdictional claims in published maps and institutional affiliations.

Copyright: (c) 2022 by the authors. Licensee MDPI, Basel, Switzerland. This article is an open access article distributed under the terms and conditions of the Creative Commons Attribution (CC BY) license (https:// creativecommons.org/licenses/by/ $4.0 /)$.

\begin{abstract}
In the last decades, experimental studies have been carried out to investigate the effects of radiofrequency (RF, $100 \mathrm{kHz}-300 \mathrm{GHz}$ ) electromagnetic fields (EMF) exposure on the apoptotic process. As evidence-based critical evaluation of RF and apoptosis in vitro is lacking, we performed a scoping literature review with the aim of systematically mapping the research performed in this area and identifying gaps in knowledge. Eligible for inclusion were in vitro studies assessing apoptosis in mammalian cells exposed to RF-EMF, which met basic quality criteria (sham control, at least three independent experiments, appropriate dosimetry analysis and temperature monitoring). We conducted a systematic literature review and charted data in order to overview the main characteristics of included studies. From the 4362 papers retrieved with our search strategy, 121 were pertinent but, among them, only 42 met basic quality criteria. We pooled data with respect to exposure (frequency, exposure level and duration) and biological parameters (cell type, endpoint), and highlighted some qualitative trends with respect to the detection of significant effect of RF-EMF on the apoptotic process. We provided a qualitative picture of the evidence accumulated so far, and highlighted that the quality of experimental methodology still needs to be highly improved.
\end{abstract}

Keywords: scoping review; radiofrequency fields; apoptosis; in vitro; quality of studies; qualitative analysis

\section{Introduction}

\subsection{Rationale}

In 2011, the International Agency for Research on Cancer (IARC) classified radiofrequency electromagnetic fields (RF-EMF, $100 \mathrm{kHz}-300 \mathrm{GHz}$ ) from mobile phones as a possible human carcinogens (2B group) based on the limited evidence from experimental and epidemiological studies [1]. From the literature published since then, and reviewed by international expert panels, the evidence for health effects due to RF-EMF exposure is still inadequate, and needs more accurate investigation [2,3]. Moreover, mechanistic insights of RF-EMF exposure have not been clarified so far for any cellular endpoint. Many hypotheses have been suggested, but none of them has been proven so far [2-5].

Among the potential cellular mechanisms that are relevant for cancer occurrence, alteration of apoptotic process is of particular interest due to the pivotal role of the regulation of apoptosis in cell homeostasis [6,7] Moreover, abnormalities in cell death regulation, whether they feature insufficient or excessive apoptosis, can be a significant component of other diseases such as autoimmune lymphoproliferative syndrome, AIDS, ischemia and neurodegenerative diseases such as Parkinson's, Alzheimer's, Huntington's diseases and Amyotrophic Lateral Sclerosis [8].

Apoptosis is an important cell death program, highly conserved within multicellular organisms and genetically controlled, which is responsible for the removal of damaged, 
dysfunctional or no longer necessary cells to promote homeostasis and survival of organisms [6-8]. Two pathways are involved in apoptosis that work synergistically to assure the removal of the defective cells. The intrinsic cell death pathway, or mitochondrial pathway, is activated by the cell itself upon detection of cell damage via a number of intracellular sensors. It is governed by the Bcl-2 family of proteins, which regulate commitment to cell death through the mitochondria and the activation of caspase 9. The extrinsic cell death pathway is activated by the interaction between a cell of the immune system and a damaged cell. Activation of the extrinsic cell death pathway occurs following the binding on the cell surface of "death receptors" such as Tumor Necrosis Factor Receptor (Fas TNFR1), or TNF-related apoptosis inducing ligand (TRAIL) receptors, to their corresponding ligands. These death receptors recruit adaptor molecules such as Fas-associated protein with death domain (FADD) and caspase 8 . Once the caspases 8 and 9 are activated by inactive pro-caspases, the two pathways converge with the activation of the executioner caspases (caspases 3, 6 and 7). At this point, a cascade of events initiates that leads to DNA fragmentation from activation of endonucleases, destruction of cytoskeleton and nuclear proteins, crosslink of proteins, the expression of ligands for recognition by phagocytic cells, such as the phosphatidylserine, and the formation of apoptotic bodies. The exposure of phosphatidylserine on the external surface of the plasma membrane allows the phagocyte recognition of the dying cells [8-10].

Different methods for the detection of apoptosis and its peculiar hallmarks (which allow the recognition with respect to the necrosis), have been developed over time concurrently with the knowledge of apoptosis phenomena. They mainly rely on morphological and biochemical analysis aimed at identifying features of apoptotic cells such as shrinkage, membrane blebbing and chromatin condensation, DNA fragmentation, detection of caspases, cleaved substrates, regulators and inhibitors, externalization of phosphatidylserine, alteration of mitochondrial membrane potential, release of cytochrome-c, analysis of apoptotic or anti-apoptotic regulator proteins such as $\mathrm{Bcl}-2$-associated $\mathrm{X}$ protein (Bax), as well as $\mathrm{BH} 3$-interacting domain death agonist (Bid), and BCL2 apoptosis regulator (Bcl 2) [8].

A number of in vitro and in vivo experimental studies have addressed the effects of exposures to RF EMF, at frequencies and signals typical of telecommunications, on the apoptotic process. These studies have been carried out under different conditions and experimental regimens with conflicting results, which have not been systematically reviewed. Several reviews regarding the effect of RF-EMF on mammalian cells included apoptosis but were not specifically focused on it [11-15]. Moreover, in all the reviews cited above, papers were not retrieved by performing a systematic literature search, and inclusion criteria did not include cogent quality parameters. The latter have been demonstrated to greatly affect the results of experimental studies. Indeed, quality is emerging as a critical issue in bioelectromagnetic research in general, since the majority of studies do not comply with quality criteria such as adequate attention to dosimetry, inclusion of sham control, positive control, blind evaluation and temperature control [16,17].

As evidence-based critical evaluation of RF exposures and apoptosis is still lacking with reference to health risk assessment, here we performed a scoping literature review, with the aim of systematically mapping the research performed in this area and identifying gaps in knowledge. We focus on in vitro studies because they can provide essential information about the potential effects of chemicals or physical agents on specific cell properties, and allow a more rapid, cost effective and well-controlled approach to molecular and mechanistic studies than conventional laboratory animal models [16]. Moreover, the preamble to the IARC Monographs on the Identification of Carcinogenic Hazards to Humans has given new emphasis and highlighted the importance of mechanistic studies in corroborating evidence and providing biological plausibility to other types of studies, and the possibility that they could provide strong evidence in case of consistent findings demonstrated across a number of different systems and in different species [1]. 


\subsection{Objective}

The aim of this scoping review is to survey the available evidence on the effects of RFEMF exposures on the apoptotic process in mammalian cells cultured in vitro by mapping how research was conducted, by identifying key characteristics of the experiments and any existing gaps in knowledge. A systematic literature search was performed and the review was restricted to studies that adhere to basic quality criteria defined a priori, and thus characterized by low risk of bias. The scientific question, formulated as a PECO (Population, Exposure, Comparator, Outcome) statement, is outlined in Table 1.

Table 1. PECO statement.

\begin{tabular}{|c|c|}
\hline Population & $\begin{array}{l}\text { In Vitro Models of Healthy or Cancerous Mammalian Cells, either } \\
\text { Immortalized or Freshly Collected via Drawing/Explant. }\end{array}$ \\
\hline Exposure & 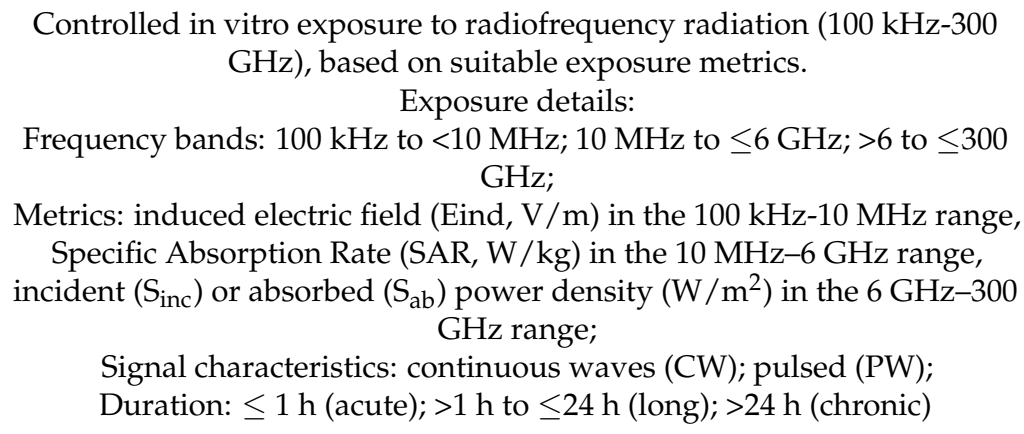 \\
\hline Comparator & Sham-exposed (sham) control samples. \\
\hline Outcome & $\begin{array}{l}\text { Apoptosis assessed by considering the following endpoints: morphological } \\
\text { hallmarks (cell shrinkage, plasma membrane blebbing, chromatin } \\
\text { condensation, etc.), alteration of mitochondrial membrane potential, } \\
\text { cytochrome-c release, translocation of phosphatidylserine, caspases } \\
\text { activation, PARP-cleavage, DNA fragmentation, apoptosis signaling (Bak, } \\
\text { Bcl-10, Bcl-2, p-53, Bax, Bid, Bag, apoptosis-inducing factor (AIF), etc.). }\end{array}$ \\
\hline
\end{tabular}

\section{Methods}

The scoping review conforms to PRISMA-ScR (Preferred Reporting Items for Systematic reviews and Meta-Analyses extension for Scoping Reviews) guidelines, provided as Supplementary Material (Table S1: PRISMA-ScR-Checklist) [18,19].

\subsection{Eligibility Criteria}

We have restricted inclusion to peer-reviewed journal articles reporting findings from primary studies and published in English. Meeting abstracts, conference proceedings, and commentaries were excluded, whereas reviews have been used to check for missing articles.

We have included in vitro studies assessing the capability of RF-EMF in the frequency range between $100 \mathrm{kHz}$ and $300 \mathrm{GHz}$, to affect apoptosis process in mammalian cells (Table 1), with no restrictions on biological model (freshly collected or immortalized cells), cell status (healthy or cancerous), or cell lineage. Regarding the apoptosis outcome, we have included the endpoints reported in the PECO statement (Table 1).

For studies that evaluate apoptosis in relation to both RF exposure alone, and to coexposure to RF fields and other agents, only findings concerning RF exposure alone have been considered, because we want to focus on potential apoptosis effects of RF-EMF themselves.

In order to restrict the analysis to papers characterized by a low risk of bias, we have adopted the following quality-based exclusion criteria [20].

First, we excluded studies that did not provide information to adequately characterize exposure conditions, such as frequency range, signal type, exposure level and duration, as detailed in the PECO statement (Table 1). We excluded studies where dosimetry analysis 
was not performed at all or was not carried out with adequate methods. For example, estimation of SAR from measurements of the electric field in absence of the sample is not appropriate because the sample significantly perturbs the electric field in the RF range. On the contrary, estimation of SAR from computation of electric field in the sample or by calorimetric measurements are acceptable $[20,21]$.

We included studies that used sham-exposed controls, i.e., a sample placed in an exposure system identical to that used to administer the treatment, except for the emission of RF-EMF [20]. A further quality-based exclusion criteria was the absence of temperature control. As a main confounding factor for RF exposure, temperature inside the samples must be monitored to ascertain absence of heating, or to counteract possible thermal increase. Finally, we also excluded studies that performed less than three independent experiments or did not report the number of independent experiments.

\subsection{Information Sources and Search Strategy}

Our primary information sources were NCBI PubMed and Web of Science (WOS) databases. In both cases, we did not apply restrictions in terms of time coverage, and the most recent search was performed on 12 August 2021. The search strategies developed for both databases are provided as Supplementary Material (Table S2: Search queries). We also checked reference lists of review papers and authors' personal literature databases to retrieve studies that were missed by the web search.

\subsection{Selection of Sources of Evidence}

All bibliographic records have been imported into the reference management software Endnote ${ }^{\circledR}$ X9, and the appropriate functions have been used to remove duplicates and classify the papers by relevance and inclusion/exclusion status. Two independent reviewers (SR and MRS) have performed a two-phase selection process: first, the papers have been included/excluded for relevance based on the screening of title and abstract; second, the full text of all potentially relevant papers has been retrieved and assessed for compliance with the predefined eligibility criteria. The results of the papers selection process have been graphically displayed in a PRISMA flow-chart, and the papers excluded at the stage of full-text examination have been recorded in a separate table, with indication of at least one motivation for exclusion.

\subsection{Data Charting Process and Data Items}

The same investigators in charge of the papers selection have also extracted the relevant information regarding the experiments, using the forms reported as Supplementary Material 3. More specifically, for each paper we have identified individual experiments, characterized by different exposure conditions (in terms of frequency, signal, exposure level or duration), or different cell models or endpoints. For each experiment, the following data have been extracted and recorded in the form:

- Complete paper reference.

- Cell type and number of independent experiments.

- Apoptosis endpoint.

- Exposure conditions: frequency, type of signal, exposure metric, exposure duration.

- Results: statistically significant effect (based on the analysis performed by the authors of the study) irrespective of the direction (increase or decrease); non statistically significant effect.

- Comment: any other information useful to further assess the quality of study (e.g., blind analysis, presence of positive control, appropriateness of statistical analysis, etc.)

\subsection{Synthesis of Results}

- We performed descriptive statistics of the selected parameters in order to characterize the experiments over the publication time by cell type (human vs. animal, primary 
cells vs. cell lines), with respect to the endpoints analyzed, and the exposure conditions. To the latter aim, we identified several subgroups within the exposure parameters:

- Frequency subgroups: $100 \mathrm{kHz}$ to $<10 \mathrm{MHz}$ (F1); $10 \mathrm{MHz}$ to $\leq 6 \mathrm{GHz}$ (F2); $>6$ to $\leq 300 \mathrm{GHz}(\mathrm{F} 3)$;

- $\quad$ Exposure duration subgroups: $\leq 1 \mathrm{~h}$ (ED1, acute); $>1 \mathrm{~h}$ to $\leq 24 \mathrm{~h}(\mathrm{ED} 2$, long); $>24 \mathrm{~h}$ (ED3, chronic, including intermittent exposure over several days);

- $\quad$ Exposure level subgroups: $S A R \leq 1 \mathrm{~W} / \mathrm{kg}$ or $\mathrm{S}_{\mathrm{ab}}<20 \mathrm{~W} / \mathrm{m}^{2}$ or $\mathrm{S}_{\text {inc }}<10 \mathrm{~W} / \mathrm{m}^{2}(\mathrm{EL1})$; $1 \mathrm{~W} / \mathrm{kg}<\mathrm{SAR} \leq 2 \mathrm{~W} / \mathrm{kg} \mathrm{S}_{\mathrm{ab}}=20 \mathrm{~W} / \mathrm{m}^{2}$ or $\mathrm{S}_{\mathrm{inc}}=10 \mathrm{~W} / \mathrm{m}^{2}(\mathrm{EL} 2) ; \mathrm{SAR}>2 \mathrm{~W} / \mathrm{kg}$ or $\mathrm{S}_{\mathrm{ab}}>20 \mathrm{~W} / \mathrm{m}^{2}$ or $\mathrm{S}_{\mathrm{inc}}>10 \mathrm{~W} / \mathrm{m}^{2}$ (EL3).

We also assessed the overall incidence of statistically significant or non-significant effects in the experiments, and the relative incidence of effects with respect to the endpoints and the exposure parameter subgroups.

\section{Results}

\subsection{Selection of Sources of Evidence}

The results of the literature search and of the screening process are summarized in the PRISMA flow-chart in Figure 1. The literature search yielded a total of 4649 records, which reduced to 4362 after duplicates removal in Endnote X9. The first round of screening, based on information and terms in the title and abstract, led to the exclusion of 4241 publications, whereas for the remaining 121 records the full text was assessed for eligibility. Among these, 79 papers were excluded because they were not compliant with either basic or quality criteria, whereas the remaining 42 were fully analyzed for data extraction and synthesis. The full references of excluded papers with motivations for exclusion are reported in Table 2.

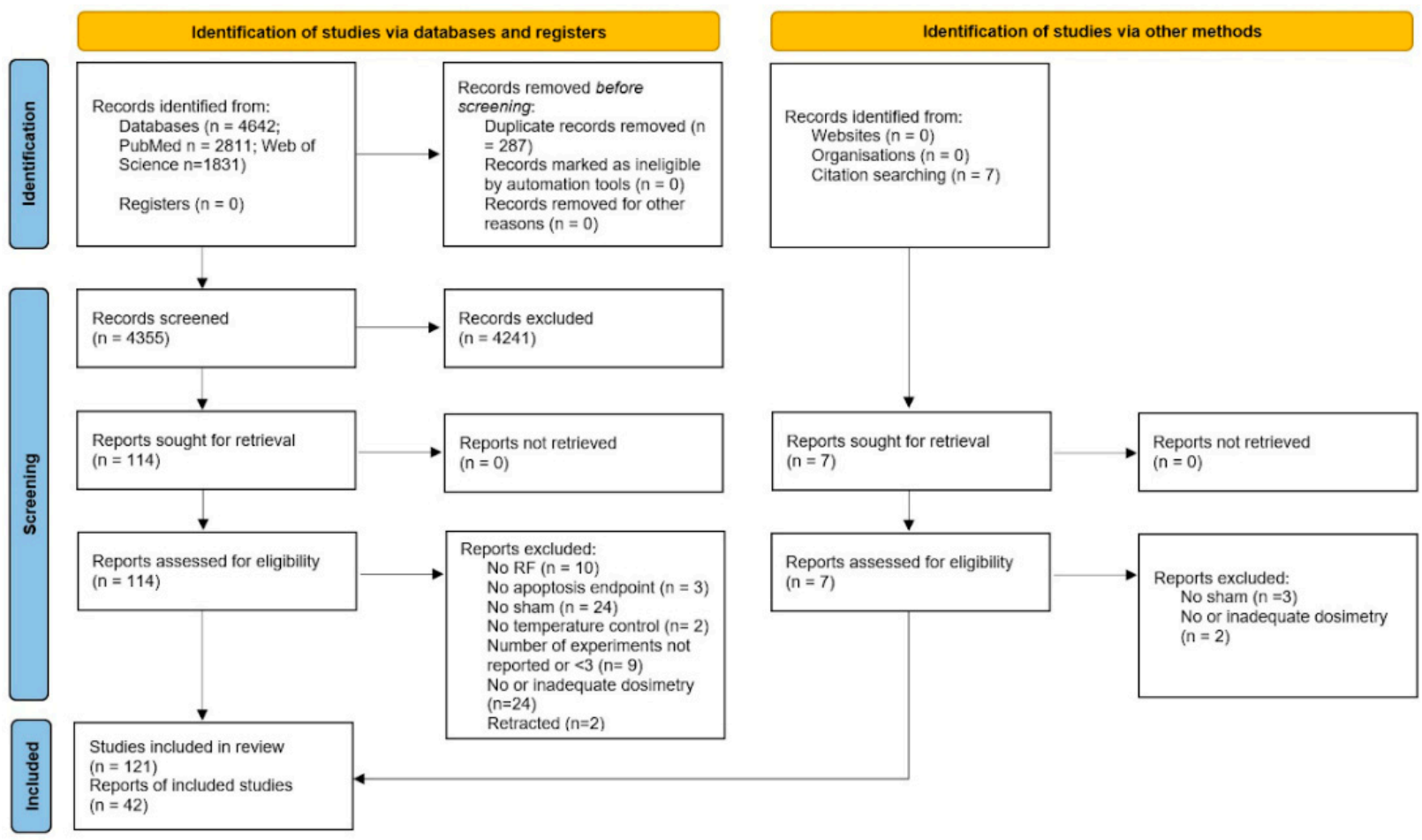

Figure 1. PRISMA flowchart. 
Table 2. Excluded papers with motivations.

\begin{tabular}{|c|c|c|}
\hline ID & Reference & Motivation(s) for Exclusion \\
\hline 1 & Alessio et al. 2019 [22] & No dosimetry \\
\hline 2 & Al-Serori et al. 2017 [23] & Less than three independent experiments. \\
\hline 3 & Asano et al., 2020 [24] & No apoptosis endpoint \\
\hline 4 & Asano et al., 2017 [25] & No sham control. Inadequate description of the RF exposure system and dosimetry. \\
\hline 5 & Atasoy et al., 2009 [26] & No sham control \\
\hline 6 & Avendano et al., 2012 [27] & No sham control \\
\hline 7 & Azma et al., 2018 [28] & No dosimetry \\
\hline 8 & Ballardin et al., 2011 [29] & No sham control \\
\hline 9 & Calabrò et al., 2012 [30] & No dosimetry \\
\hline 10 & Cao et al., 2009 [31] & No sham control \\
\hline 11 & Caraglia et al., 2005 [32] & No sham control \\
\hline 12 & Çiğ and Naziroğlu, 2015 [33] & No sham control \\
\hline 13 & Eghlidospour et al., 2017 [34] & No dosimetry \\
\hline 14 & Esmekaya et al., 2013 [35] & Number of independent experiments not reported \\
\hline 15 & Esmekaya et al., 2017 [36] & No temperature control \\
\hline 16 & Falzone et al., 2010 [37] & No sham control \\
\hline 17 & Glazer et al., 2010 [38] & Thermal effect \\
\hline 18 & Grasso et al., 2020 [39] & No dosimetry \\
\hline 19 & Harvey and French, 2000 [40] & Less than three independent experiments \\
\hline 20 & Hirose et al., 2006 [41] & Less than three independent experiments \\
\hline 21 & Jin et al., 2012 [42] & Less than three independent experiments \\
\hline 22 & Jin et al., 2021 [43] & No sham control \\
\hline 23 & Jooyan et al., 2019 [44] & No sham control \\
\hline 24 & Kahya et al., 2014 [45] & No sham control \\
\hline 25 & Karaca et al., 2012 [46] & No sham control \\
\hline 26 & Karkabounas et al., 2006 [47] & No dosimetry \\
\hline 27 & Kayhan et al., 2016 [48] & No dosimetry \\
\hline 28 & Keczan et al., 2016 [49] & Not RF range \\
\hline 29 & Kim et al., 2021 [50] & No sham control \\
\hline 30 & Korraah et al., 2012 [51] & Not RF range \\
\hline 31 & Koshkina et al., 2014 [52] & Thermal effect \\
\hline 32 & Lantow et al., 2006 [53] & Not apoptosis \\
\hline 33 & Lee et al., 2016 [54] & Number of independent experiments not reported \\
\hline 34 & Lee et al., 2005 [55] & Number of independent experiments not reported \\
\hline 35 & Lee et al., 2014 [56] & No sham control \\
\hline 36 & Leszczynski et al., 2002 [57] & No apoptosis endpoint \\
\hline 37 & Li et al., 2014 [58] & No dosimetry \\
\hline 38 & Li et al. 2010 [59] & Only combined exposures \\
\hline 39 & Li et al. 2011 [60] & Not RF range \\
\hline
\end{tabular}


Table 2. Cont.

\begin{tabular}{|c|c|c|}
\hline ID & Reference & Motivation(s) for Exclusion \\
\hline 40 & Li et al. 2012 [61] & No dosimetry \\
\hline 41 & Liang et al., 2013 [62] & No dosimetry \\
\hline 42 & Liu et al., 2011 [63] & Inadequate description of the RF exposure system and dosimetry. \\
\hline 43 & Liu et al., 2012 [64] & No sham control \\
\hline 44 & Liu et al., 2015 [65] & No sham control \\
\hline 45 & Lu et al., 2012 [66] & No sham control. \\
\hline 46 & Maioli et al., 2013 [67] & No sham control. No dosimetry \\
\hline 47 & Marinelli et al., 2004 [68] & Absence of appropriate dosimetry methods \\
\hline 48 & Martin et al., 2009 [69] & Absence of appropriate exposure metrics and dosimetry \\
\hline 49 & Mortazavi et al., 2015 [70] & Absence of appropriate exposure metrics and dosimetry \\
\hline 50 & Naziroglu et al., 2015 [71] & No sham control \\
\hline 51 & Narvaez et al., 2018 [72] & Absence of appropriate exposure metrics and dosimetry \\
\hline 52 & Nishioka et al., 2020 [73] & Absence of appropriate exposure metrics and dosimetry \\
\hline 53 & Oh et al., 2001 [74] & Not RF range \\
\hline 54 & Ozgur et al., 2014 [75] & Number of independent experiments not reported \\
\hline 55 & Ozsobaci et al., 2020 [76] & Absence of appropriate exposure metrics and dosimetry \\
\hline 56 & Pacini et al., 2002 [77] & No dosimetry \\
\hline 57 & Pastacı Özsobacı et al., 2018 [78] & No sham control. Number of experiments not reported \\
\hline 58 & Peinnequin et al., 2000 [79] & No dosimetry \\
\hline 59 & Port et al., 2003 [80] & No sham control \\
\hline 60 & Radeva et al., 2009 [81] & Not RF range \\
\hline 61 & Solek et al., 2017 [82] & Not RF range \\
\hline 62 & Song et al., 2011 [83] & No sham control \\
\hline 63 & $\begin{array}{l}\text { Sueiro-Benavides et al., } 2021 \\
\text { [84] }\end{array}$ & No sham control \\
\hline 64 & Tomruk et al., 2019 [85] & $\begin{array}{l}\text { Inadequate description of dosimetry. Sham exposures was likely, not concurrent to RF } \\
\text { exposure }\end{array}$ \\
\hline 65 & Urnukhsaikhan et al., 2016 [86] & Not RF range \\
\hline 66 & Volkova et al., 2014 [87] & No dosimetry \\
\hline 67 & Wu et al., $2011[88]$ & No sham control \\
\hline 68 & Wu et al., 2012 [89] & No dosimetry \\
\hline 69 & Wu et al. $2012[90]$ & Retracted \\
\hline 70 & Xing et al., 2016 [91] & No dosimetry \\
\hline 71 & Yang et al., 2012 [92] & No sham control \\
\hline 72 & Yao et al. [93] & Retracted \\
\hline 73 & Zhang et al., 2013 [94] & Inadequate description of the RF exposure system and dosimetry. \\
\hline 74 & Zhao et al., 2007 [95] & Inadequate description of the RF exposure system and dosimetry. \\
\hline 75 & Zhao et al., 2017 [96] & No information on dosimetry \\
\hline 76 & Zhijian et al., 2013 [97] & Less than three independent experiments \\
\hline 77 & Zhou et al., 2008 [98] & No sham control. \\
\hline 78 & Zhu et al., 2014 [99] & No sham control. No dosimetry performed. \\
\hline 79 & Zuo et al., 2015 [100] & No temperature control at $18 \mathrm{~W} / \mathrm{kg}$ SAR. \\
\hline
\end{tabular}


Figure 2 shows the number of included, excluded and retracted studies, and the motivations for exclusion with relative proportions (when more than one motivation applied, only one of them was counted): the most recurrent motivations were the absence of sham control and the absence of dosimetry or of appropriate dosimetry methods.

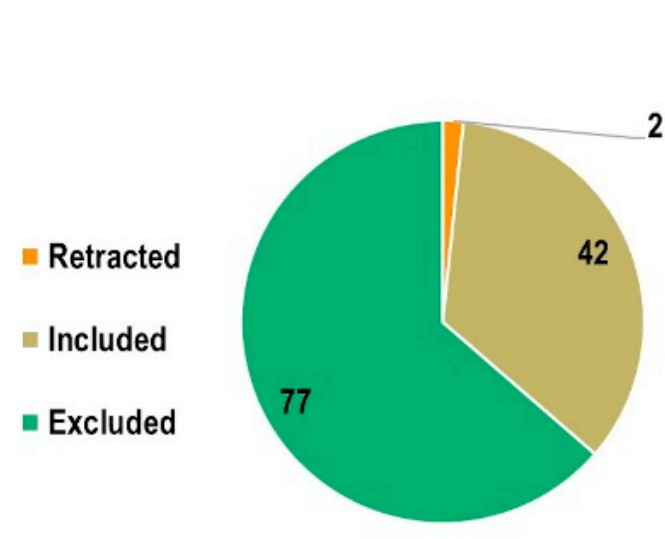

(a)

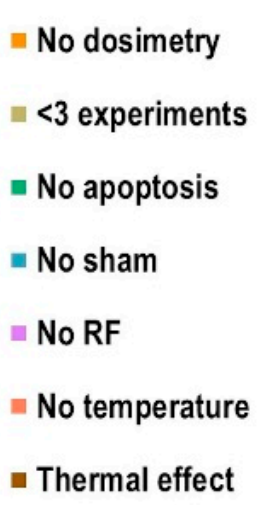

- Thermal effect

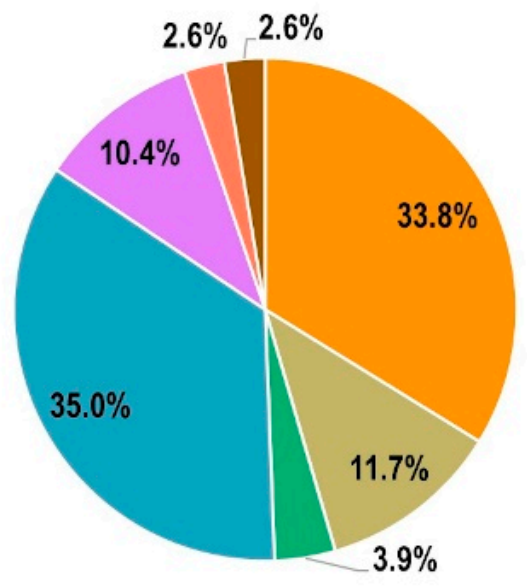

(b)

Figure 2. (a) Number of included, excluded and retracted studies; (b) motivations for exclusion with relative proportions.

\subsection{Characteristics of Sources of Evidence}

Figure 3 reports the temporal trend of publication of the included and excluded studies. The first studies were published in 2000 (2004, if we consider relevant studies that were included based on our quality criteria), meaning that this topic has been addressed in the literature for a relatively short time.

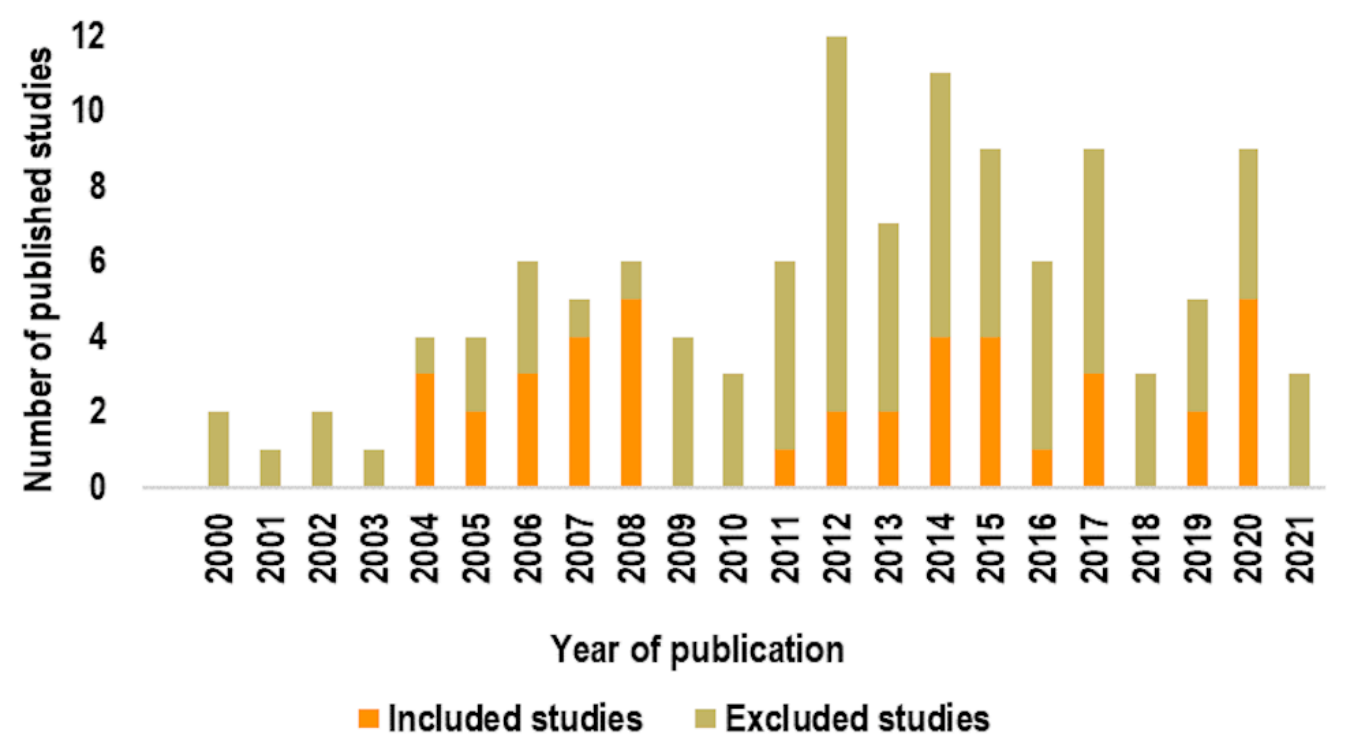

Figure 3. Temporal trend of publication of studies.

The main characteristics of included studies are charted in Tables 3 and 4. We have separated studies into two categories. First, those that did not observe statistically significant (according to the statistical analysis performed by the authors) alterations of the apoptotic process due to RF-EMF exposures in any of the experimental conditions considered (Table 3). Secondly, those that did report significant alterations in at least one of the experimental conditions considered (Table 4). 
Table 3. Overview of studies that did not report statistically significant alterations of the apoptotic process following RF-EMF exposures.

\begin{tabular}{|c|c|c|c|c|c|c|}
\hline ID & Reference & Cell Type & Biological Endpoint & Exposure Conditions & Results & Comment \\
\hline 1 & Belyaev et al., 2005 [101] & Human blood lymphocytes & $\begin{array}{l}\text { DNA fragmentation } \\
\text { Morphological } \\
\text { hallmarks }\end{array}$ & $\begin{array}{l}915 \mathrm{MHz}(\mathrm{GSM}) \\
0.037 \mathrm{~W} / \mathrm{kg} \\
2 \mathrm{~h}\end{array}$ & No effect & - \\
\hline 2 & Bourthomieu et al., 2013 [102] & Primary human amniotic cells & Apoptosis signaling & $\begin{array}{l}900 \mathrm{MHz}(\mathrm{GSM}) \\
0.25,1,2,4 \mathrm{~W} / \mathrm{kg} \\
24 \mathrm{~h}\end{array}$ & No effect & Non-blinded analysis \\
\hline 3 & Capri et al., 2004a [103] & Human blood mononuclear cells & $\begin{array}{l}\text { PE } \\
\text { MMP modification }\end{array}$ & $\begin{array}{l}1800 \mathrm{MHz} \text { (GSM-basic, GSM-talk, DTX) } \\
1.4 \text { and } 2 \mathrm{~W} / \mathrm{kg} \\
44 \mathrm{~h}(10 \mathrm{~min} \text { on } / 20 \mathrm{~min} \text { off cycles })\end{array}$ & No effect & - \\
\hline 4 & Capri et al., 2004b [104] & Human blood mononuclear cells & $\begin{array}{l}\text { PE } \\
\text { MMP modification }\end{array}$ & $\begin{array}{l}900 \mathrm{MHz}(\mathrm{CW} \text { and } \mathrm{GSM}) \\
0.07 \text { and } 0.076 \mathrm{~W} / \mathrm{kg} \\
1 \mathrm{~h} / \text { day for } 3 \text { days }\end{array}$ & No effect & Non-blinded analysis \\
\hline 5 & Chauhan et al., 2007 [105] & $\begin{array}{l}\text { Human-derived immune cell } \\
\text { lines (HL-60, Mono-Mac-6, TK6) }\end{array}$ & DNA fragmentation & $\begin{array}{l}1900 \mathrm{MHz}(\mathrm{PM}) \\
1 \text { and } 10 \mathrm{~W} / \mathrm{kg} \\
6 \mathrm{~h}(5 \mathrm{~min} \text { on } / 10 \mathrm{~min} \text { off cycles })\end{array}$ & No effect & - \\
\hline 6 & Chen et al., 2014 [106] & $\begin{array}{l}\text { Embryonic mouse neural stem } \\
\text { (eNSCs) cells }\end{array}$ & $\begin{array}{l}\text { DNA fragmentation } \\
\text { Caspase activity } \\
\text { Apoptosis signaling }\end{array}$ & $\begin{array}{l}1800 \mathrm{MHz} \\
4 \mathrm{~W} / \mathrm{kg} \\
3 \text { days ( } 5 \text { min on } / 10 \text { min off cycles) }\end{array}$ & No effect & - \\
\hline 7 & Choi et al., 2020 [107] & $\begin{array}{l}\text { Human adipose tissue-derived } \\
\text { stem (ASCs) cells, liver cancer } \\
\text { stem cells (Huh7) }\end{array}$ & PARP cleavage & $\begin{array}{l}1700 \mathrm{MHz}(\mathrm{LTE}) \\
1 \text { and } 2 \mathrm{~W} / \mathrm{kg} \\
72 \mathrm{~h}\end{array}$ & No effect & Non-blinded analysis \\
\hline 8 & De Amicis et al., 2015 [108] & $\begin{array}{l}\text { Human primary fibroblasts } \\
\text { HFFF2 }\end{array}$ & PARP cleavage & $\begin{array}{l}120 \mathrm{THz}(\mathrm{PW}) \\
4 \mathrm{~W} / \mathrm{m}^{2}(0.015-0.022 \mathrm{~W} / \mathrm{g}) \\
20 \mathrm{~min}\end{array}$ & No effect & $\begin{array}{l}\text { Non-blinded analysis } \\
\text { No positive control }\end{array}$ \\
\hline 9 & Durdik et al., 2019 [109] & $\begin{array}{l}\text { Umbilical cord blood (UCB) } \\
\text { cells }\end{array}$ & $\mathrm{PE}$ & $\begin{array}{l}900 \mathrm{MHz}(\mathrm{GSM}), 1950 \mathrm{MHz} \text { (UMTS) } \\
4 \text { and } 40 \mathrm{~W} / \mathrm{kg} \\
2 \mathrm{~h}\end{array}$ & No effect & Non-blinded analysis \\
\hline 10 & Glaser et al., 2016 [110] & $\begin{array}{l}\text { Hematopoietic stem cells (HSC); } \\
\text { promyelocytic leukemia cell line } \\
\text { (HL-60) }\end{array}$ & PE & $\begin{array}{l}900 \mathrm{MHz}(\mathrm{GSM}), 1950 \mathrm{MHz} \text { (UMTS), } 2535 \\
\mathrm{MHz}(\mathrm{LTE}) \\
0.5,1,2 \text { and } 4 \mathrm{~W} / \mathrm{kg} \\
4 \text { and } 20 \mathrm{~h}(\mathrm{HSC}) \\
4 \text { and } 66 \mathrm{~h}(\mathrm{HL}-60)\end{array}$ & No effect & $\begin{array}{l}\text { Sham and RF } \\
\text { samples were not } \\
\text { run concurrently }\end{array}$ \\
\hline
\end{tabular}


Table 3. Cont.

\begin{tabular}{|c|c|c|c|c|c|c|}
\hline ID & Reference & Cell Type & Biological Endpoint & Exposure Conditions & Results & Comment \\
\hline 11 & Gulati et al., 2020 [111] & $\begin{array}{l}\text { Human peripheral blood } \\
\text { lymphocytes }\end{array}$ & $\mathrm{PE}$ & $\begin{array}{l}923,1947.47,1977 \mathrm{MHz} \text { (UMTS) } \\
0.04 \mathrm{~W} / \mathrm{kg} \\
1 \mathrm{~h} \text { and } 3 \mathrm{~h}\end{array}$ & No effect & $\begin{array}{l}\text { Non-blinded analysis } \\
\text { No positive control }\end{array}$ \\
\hline 12 & Gurisik et al., 2006 [112] & $\begin{array}{l}\text { Promyelocytic leukemia cell line } \\
\text { (HL-60) } \\
\text { Human neuroblastoma cells } \\
\text { (SK-N-SH) }\end{array}$ & Membrane integrity & $\begin{array}{l}900 \mathrm{MHz}(\mathrm{GSM}) \\
0.2 \mathrm{~W} / \mathrm{kg} \\
2 \mathrm{~h}\end{array}$ & No effect & $\begin{array}{l}\text { Non-blinded analysis } \\
\text { No positive control }\end{array}$ \\
\hline 13 & Hook et al., 2004 [113] & Lymphoblastoid Molt-4 cells & $\mathrm{PE}$ & $\begin{array}{l}812.56 \mathrm{MHz} \text { (iDEN) } \\
24 \mathrm{~W} / \mathrm{kg} \\
836.55 \mathrm{MHz} \text { (TDMA) } \\
26 \mathrm{~W} / \mathrm{kg} ; \\
847.74 \mathrm{MHz} \text { (CDMA) } 835.62 \mathrm{MHz} \text { (FDMA) } \\
3.2 \mathrm{~W} / \mathrm{kg} \\
2,3,21 \mathrm{~h}\end{array}$ & No effect & Non-blinded analysis \\
\hline 14 & Hoyto et al., 2008a [114] & $\begin{array}{l}\text { Human neuroblastoma } \\
\text { (SH-SY5Y); Mouse fibroblasts } \\
\text { (L929) }\end{array}$ & $\begin{array}{l}\text { Caspase activity } \\
\text { DNA fragmentation }\end{array}$ & $\begin{array}{l}872 \mathrm{MHz}(\mathrm{CW} \text { and GSM) } \\
5 \mathrm{~W} / \mathrm{kg} \\
24 \mathrm{~h}\end{array}$ & No effect & Non-blinded analysis \\
\hline 16 & Joubert et al., 2008 [116] & $\begin{array}{l}\text { Human neuroblastoma } \\
\text { (SH-SY5Y) cells }\end{array}$ & $\begin{array}{l}\text { Morphological } \\
\text { hallmarks } \\
\text { Caspase activity } \\
\text { DNA fragmentation } \\
\text { Apoptosis signaling }\end{array}$ & $\begin{array}{l}900 \mathrm{MHz}(\mathrm{CW}) \\
2 \mathrm{~W} / \mathrm{kg} \\
900 \mathrm{MHz}(\mathrm{GSM}) \\
0.25 \mathrm{~W} / \mathrm{kg} \\
24 \mathrm{~h}\end{array}$ & No effect & Non-blinded analysis \\
\hline 17 & Joubert et al., 2007 [117] & Primary rat cortical neurons & $\begin{array}{l}\text { Morphological } \\
\text { hallmarks } \\
\text { Caspase activity } \\
\text { DNA fragmentation }\end{array}$ & $\begin{array}{l}900 \mathrm{MHz}(\mathrm{GSM}) \\
0.25 \mathrm{~W} / \mathrm{kg} \\
24 \mathrm{~h}\end{array}$ & No effect & Non-blinded analysis \\
\hline 18 & Lin et al., 2017 [118] & Mouse Leydig cells & PE & $\begin{array}{l}1950 \mathrm{MHz} \text { (GSM-talk) } \\
3 \mathrm{~W} / \mathrm{kg} \\
24 \mathrm{~h}\end{array}$ & No effect & $\begin{array}{l}\text { Non-blinded analysis } \\
\text { No positive control }\end{array}$ \\
\hline
\end{tabular}


Table 3. Cont.

\begin{tabular}{|c|c|c|c|c|c|c|}
\hline ID & Reference & Cell Type & Biological Endpoint & Exposure Conditions & Results & Comment \\
\hline 19 & Liu et al., 2014 [119] & $\begin{array}{l}\text { Mouse spermatocyte-derived } \\
(\text { GC-2) cells }\end{array}$ & $\mathrm{PE}$ & $\begin{array}{l}1800 \mathrm{MHz}(\mathrm{GSM}) \\
1,2,4 \mathrm{~W} / \mathrm{kg} \\
24 \mathrm{~h}(5 \mathrm{~min} \text { on } / 10 \mathrm{~min} \text { off cycles })\end{array}$ & No effect & No positive control \\
\hline 21 & Moquet et al., 2008 [121] & $\begin{array}{l}\text { Murine neuroblastoma (N2a) } \\
\text { cells }\end{array}$ & $\begin{array}{l}\text { Caspase activity } \\
\text { DNA fragmentation } \\
\text { PE }\end{array}$ & $\begin{array}{l}935 \mathrm{MHz}(\mathrm{CW}, \mathrm{GSM}-\text { basic, GSM-talk) } \\
2 \mathrm{~W} / \mathrm{kg} \\
24 \mathrm{~h}\end{array}$ & No effect & - \\
\hline 22 & Palumbo et al., 2008 [122] & $\begin{array}{l}\text { Human lymphocytes; human } \\
\text { lymphoblastoid (Jurkat) cells }\end{array}$ & $\begin{array}{l}\text { Caspase activity } \\
\text { PARP cleavage } \\
\text { PE }\end{array}$ & $\begin{array}{l}900 \mathrm{MHz}(\mathrm{GSM}) \\
1.35 \mathrm{~W} / \mathrm{kg} \\
1 \mathrm{~h}\end{array}$ & $\begin{array}{l}\text { Increase in } \\
\text { caspase-3 } \\
\text { activity in } \\
\text { proliferating } \\
\text { but not in } \\
\text { resting cells. } \\
\text { No effect on } \\
\text { PARP cleavage } \\
\text { and PE. }\end{array}$ & $\begin{array}{l}\text { Increase in caspase-3 } \\
\text { activity not related to } \\
\text { apoptosis. }\end{array}$ \\
\hline 23 & Sanchez et al., 2007 [123] & $\begin{array}{l}\text { Human skin cells and } \\
\text { reconstructed human epidermis }\end{array}$ & $\mathrm{PE}$ & $\begin{array}{l}900 \mathrm{MHz}(\mathrm{GSM}) \\
2 \mathrm{~W} / \mathrm{kg} \\
48 \mathrm{~h}\end{array}$ & No effect & Non-blinded analysis \\
\hline 24 & Sanchez et al., 2006 [124] & Primary human skin cells & PE & $\begin{array}{l}1800 \mathrm{MHz}(\mathrm{GSM}) \\
2 \mathrm{~W} / \mathrm{kg} \\
48 \mathrm{~h}\end{array}$ & No effect & Non-blinded analysis \\
\hline 25 & Simon et al., 2013 [125] & $\begin{array}{l}\text { Primary human melanocytes } \\
\text { and keratinocytes cells }\end{array}$ & $\begin{array}{l}\text { Morphological } \\
\text { hallmarks } \\
\text { Caspase activity } \\
\text { Apoptosis signaling }\end{array}$ & $\begin{array}{l}900 \mathrm{MHz}(\mathrm{GSM}) \\
2 \mathrm{~W} / \mathrm{kg} \\
6 \mathrm{~h}\end{array}$ & No effect & $\begin{array}{l}\text { Non-blinded analysis } \\
\text { No positive control }\end{array}$ \\
\hline 26 & Terro et al., 2012 [126] & $\begin{array}{l}\text { Primary cerebral cortical cells of } \\
\text { rat embryos }\end{array}$ & $\begin{array}{l}\text { Morphological } \\
\text { hallmarks } \\
\text { Caspase activity }\end{array}$ & $\begin{array}{l}900 \mathrm{MHz}(\mathrm{GSM}) \\
0.25 \mathrm{~W} / \mathrm{kg} 24 \mathrm{~h}\end{array}$ & No effect & Non-blinded analysis \\
\hline
\end{tabular}


Table 3. Cont.

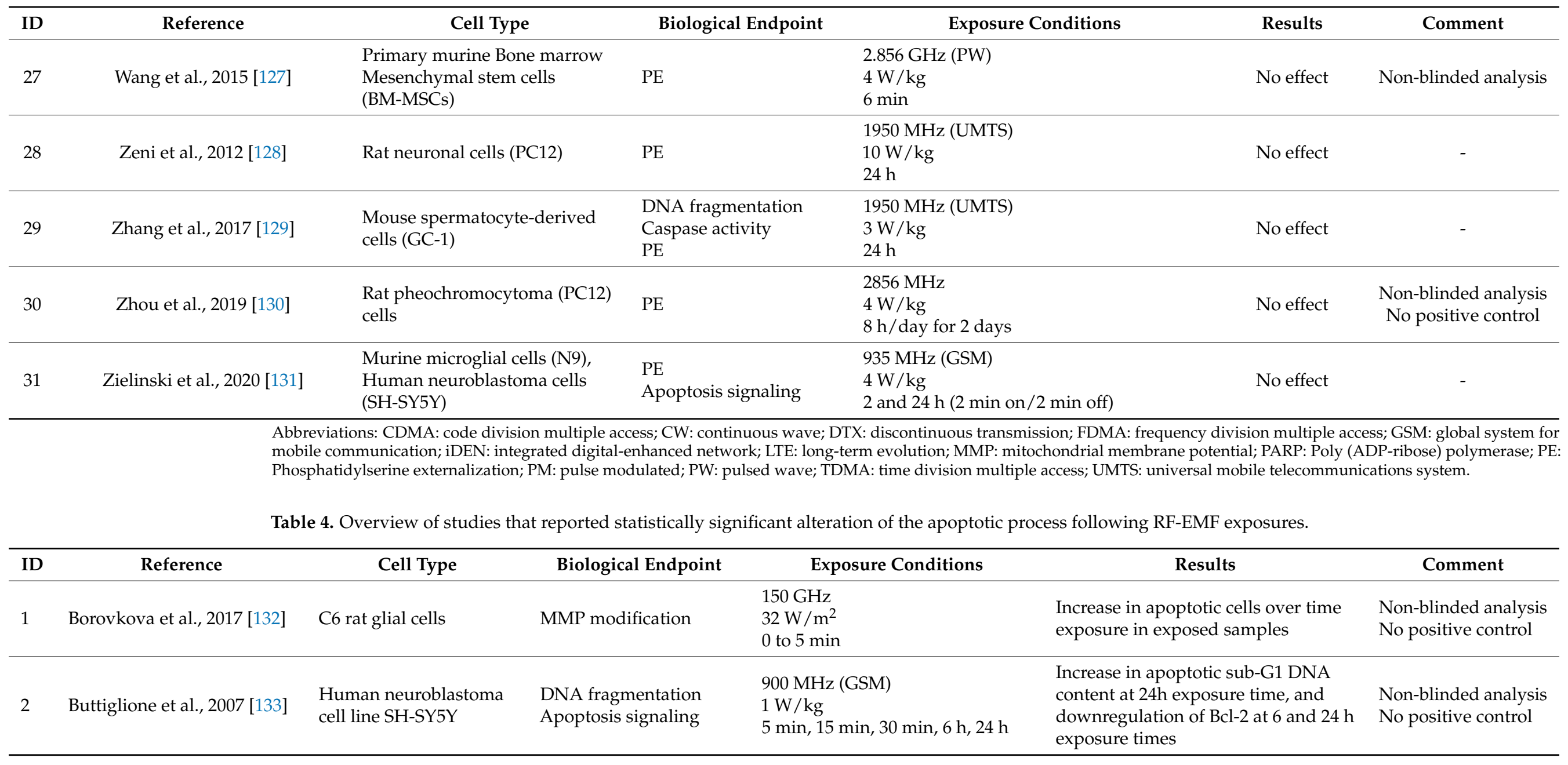


Table 4. Cont.

\begin{tabular}{|c|c|c|c|c|c|c|}
\hline ID & Reference & Cell Type & Biological Endpoint & Exposure Conditions & Results & Comment \\
\hline 3 & Canseven et al., 2015 [134] & $\begin{array}{l}\text { Burkitt's lymphoma } \\
\text { (Raji) cells }\end{array}$ & $\mathrm{PE}$ & $\begin{array}{l}1800 \mathrm{MHz}(\mathrm{GSM}) \\
0.35 \mathrm{~W} / \mathrm{kg} \\
24 \mathrm{~h}\end{array}$ & Increased apoptosis by RF & No positive control \\
\hline 4 & Hou et al., 2015 [135] & $\begin{array}{l}\text { Mouse embryonic } \\
\text { fibroblasts (NIH/3T3) }\end{array}$ & PE & $\begin{array}{l}1800 \mathrm{MHz} \text { (GSM talk- mode) } \\
2 \mathrm{~W} / \mathrm{kg} \\
0.5-8 \mathrm{~h}(5 \mathrm{~min} \text { on } / 30 \mathrm{~min} \text { off } \\
\text { cycles })\end{array}$ & $\begin{array}{l}\text { Increased apoptosis after } 1,4 \text { and } 8 \mathrm{~h} \\
\text { RF exposure; no effect after } 0.5,2 \text { and } \\
6 \mathrm{~h} \text {. }\end{array}$ & $\begin{array}{l}\text { Non-blinded analysis } \\
\text { No positive control }\end{array}$ \\
\hline 5 & Joubert et al., 2006 [136] & $\begin{array}{l}\text { Primary rat cortical } \\
\text { neurons }\end{array}$ & $\begin{array}{l}\text { Morphological } \\
\text { hallmarks } \\
\text { Caspase activity } \\
\text { DNA fragmentation }\end{array}$ & $\begin{array}{l}900 \mathrm{MHz}(\mathrm{CW}) \\
2 \mathrm{~W} / \mathrm{kg} \\
24 \mathrm{~h}\end{array}$ & $\begin{array}{l}\text { Increased apoptosis (morphological } \\
\text { hallmarks and DNA fragmentation) } \\
\text { immediately after and } 24 \mathrm{~h} \text { post-RF } \\
\text { exposure; no effect on caspase-3 } \\
\text { activity; increase in AIF-positive } \\
\text { nuclei soon after and } 24 \mathrm{~h} \\
\text { post-exposure. }\end{array}$ & $\begin{array}{l}2{ }^{\circ} \mathrm{C} \text { increase in } \\
\text { RF-exposed cultures. } \\
\text { Thermal effects } \\
\text { excluded by ad hoc } \\
\text { experiments. }\end{array}$ \\
\hline 6 & Li et al., 2020 [137] & $\begin{array}{l}\text { Mouse embryonic } \\
\text { fibroblasts NIH/3T3 }\end{array}$ & $\begin{array}{l}\text { PE } \\
\text { Apoptosis signaling }\end{array}$ & $\begin{array}{l}1800 \mathrm{MHz} \\
2 \mathrm{~W} / \mathrm{kg} \\
12,24,36,48 \mathrm{~h}(5 \mathrm{~min} \text { on } / 10 \mathrm{~min} \\
\text { off })\end{array}$ & $\begin{array}{l}\text { Increased apoptosis after } 48 \text { h RF } \\
\text { exposure; no effect after } 12,24 \text { and } 36 \\
\text { h. }\end{array}$ & $\begin{array}{l}\text { Non-blinded analysis } \\
\text { No positive control }\end{array}$ \\
\hline 7 & Nikolova et al., 2005 [138] & $\begin{array}{l}\text { Mouse neural progenitor } \\
\text { stem cells }\end{array}$ & $\begin{array}{l}\text { DNA fragmentation } \\
\text { MMP modification } \\
\text { Apoptosis signaling }\end{array}$ & $\begin{array}{l}1710 \mathrm{MHz}(\mathrm{GSM}) \\
1.5 \mathrm{~W} / \mathrm{kg} \\
48 \mathrm{~h} \text { (5 min on } / 30 \mathrm{~min} \text { off cycles) }\end{array}$ & $\begin{array}{l}\text { Upregulation of some genes. No } \\
\text { effect on other parameters } \\
\text { investigated. }\end{array}$ & No positive control \\
\hline 8 & Sefidbakht et al., 2014 [139] & $\begin{array}{l}\text { Human embryonic } \\
\text { kidney (HEK293T) cells }\end{array}$ & Caspase activity & $\begin{array}{l}940 \mathrm{MHz} \\
0.09 \mathrm{~W} / \mathrm{kg} \\
15,30,45,60 \text { and } 90 \mathrm{~min}\end{array}$ & $\begin{array}{l}\text { Increase after } 45 \text { and } 90 \mathrm{~min} R F \\
\text { exposure; no effect after 15, } 30 \text { and } 60 \\
\text { min exposure. }\end{array}$ & $\begin{array}{l}\text { Non-blinded analysis } \\
\text { No positive control }\end{array}$ \\
\hline 9 & Yoon et al., 2011 [140] & $\begin{array}{l}\text { Human dermal papilla } \\
\text { cells }\end{array}$ & Apoptosis signaling & $\begin{array}{l}1763 \mathrm{MHz}(\mathrm{CDMA}) \\
10 \mathrm{~W} / \mathrm{kg} \\
1 \mathrm{~h} / \text { day for } 7 \text { days }\end{array}$ & $\begin{array}{l}\text { Increased expression of Bcl-2 and } \\
\text { phosphorylation of MAPK-1. }\end{array}$ & $\begin{array}{l}\text { Non-blinded analysis } \\
\text { No positive control }\end{array}$ \\
\hline
\end{tabular}


Table 4. Cont.

\begin{tabular}{|c|c|c|c|c|c|c|}
\hline ID & Reference & Cell Type & Biological Endpoint & Exposure Conditions & Results & Comment \\
\hline 10 & Zhao et al., 2020 [141] & $\begin{array}{l}\text { A375 Human Melanoma } \\
\text { Cells }\end{array}$ & $\begin{array}{l}\text { PE } \\
\text { Caspase activity }\end{array}$ & $\begin{array}{l}35.2 \mathrm{GHz} \\
1.6 \mathrm{~W} / \mathrm{m}^{2} \\
15 / 30 / 60 / 90 \mathrm{~min}\end{array}$ & $\begin{array}{l}\text { Increase in apoptosis (PE) at all } \\
\text { exposure durations. Upregulation of } \\
\text { caspase- } 3 \text { and caspase- } 8\end{array}$ & $\begin{array}{l}\text { Non-blinded analysis } \\
\text { No positive control }\end{array}$ \\
\hline
\end{tabular}

Abbreviations: AIF: apoptosis inducing factor; Bcl-2: B-cell lymphoma 2; CDMA: code division multiple access; CW: continuous wave; GSM: global system for mobile communication; MAPK-1: mitogen-activated protein kinase-1; MMP: mitochondrial membrane potential; PARP: Poly (ADP-ribose) polymerase; PE: Phosphatidylserine externalization 
A total of 255 experiments were extracted from the 42 papers analyzed. Each experiment was identified on the basis of either one of the exposure parameters (frequency, signal, exposure level or duration), or of the cell type, or of the endpoint analyzed. Data extracted from each experiment are provided as Supplementary Material (Table S3: Data extracted from experiments).

\subsection{Results and Critical Appraisal of the Source of Evidence}

We surveyed the data extracted from included studies with respect to relevant parameters, namely the cell origin (human vs. animal, primary vs. cell lines), the endpoints analyzed, the frequency, exposure level and exposure duration subgroups, the reporting of statistically significant effects.

As shown in Figure 4, human cells were used as biological model more than animal cells $(72.5 \%$ vs. $27.5 \%)$, whereas in both cases immortalized cell lines $(81.6 \%$ human and $85.7 \%$ animal) were mainly used with respect to primary cells $(18.4 \%$ human, $14.3 \%$ animal). The percentage of endpoints analyzed were as reported in Figure 5, where the vast majority $(44.3 \%)$ of experiments assessed apoptosis by analyzing the phosphatidylserine externalization, followed by apoptosis signaling (18.8\%), caspase activity $(12.6 \%)$, and DNA fragmentation (10.6\%). The remaining 13.7\% accounted for the other considered apoptosis endpoints, namely alteration of mitochondrial membrane potential (4.7\%), morphological hallmarks (3.9\%), PARP cleavage $(3.9 \%)$, membrane integrity $(0.8 \%)$, and expression of cytochrome-c $(0.4 \%)$.

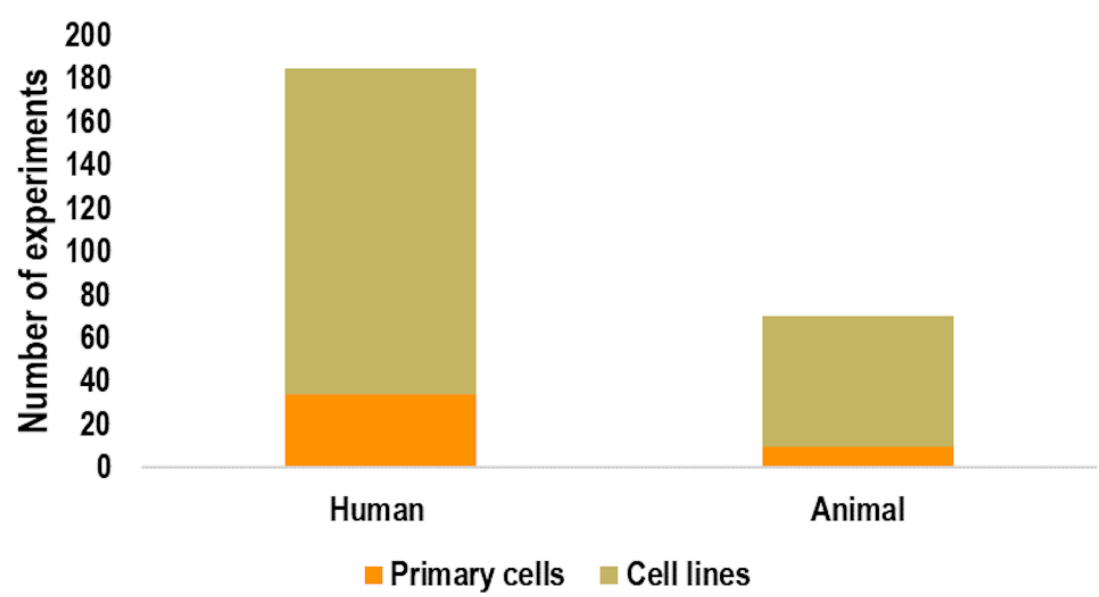

Figure 4. Number of experiments using animal or human cells. For each group, the number of experiments using primary cells vs. cell lines is also reported.
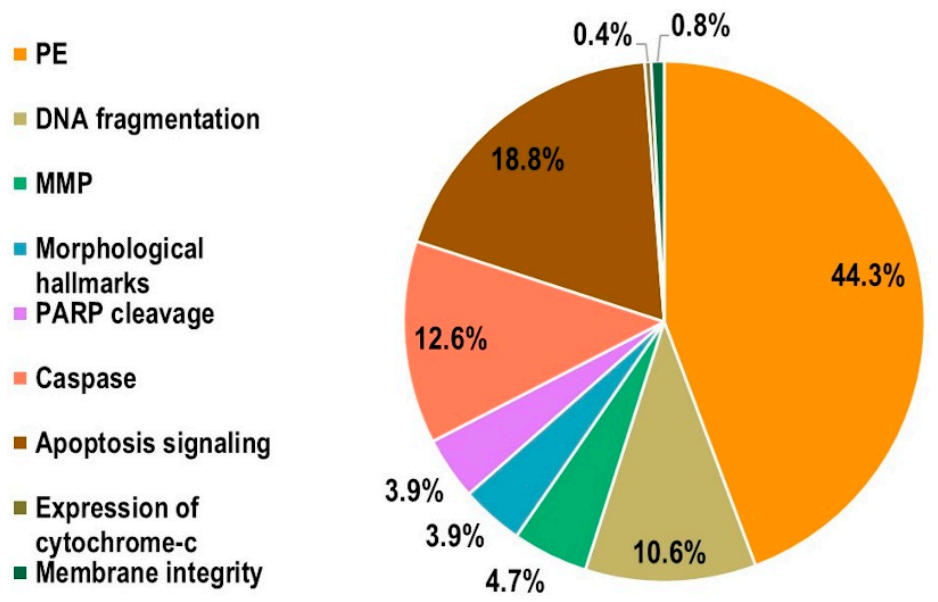

Figure 5. Percentage of endpoints analyzed in the experiments (MMP: mitochondrial membrane potential; PE: phosphatidylserine externalization; PARP: Poly(ADP-Ribose) Polymerase). 
Figure 6 shows the percentage of experiments belonging to the three subgroups (as defined in Table 1) within the main exposure parameters (frequency, exposure level and exposure duration). The majority of the experiments $(94.5 \%)$ were performed by applying EMF in the F2 subgroup (10 MHz to $\leq 6 \mathrm{GHz})$, only $5.5 \%$ of them applied EMF in the F3 ( $>6$ to $\leq 300 \mathrm{GHz}$ ) subgroup, and none of them employed frequencies below $10 \mathrm{MHz}(\mathrm{F} 1)$. The distribution within the exposure level subgroups was definitely more uniform, with $38.4 \%$ of experiments performed at $\mathrm{SAR}<1 \mathrm{~W} / \mathrm{kg}$ or $\mathrm{S}_{\mathrm{ab}}<20 \mathrm{~W} / \mathrm{m}^{2}$ or $\mathrm{S}_{\text {inc }}<10 \mathrm{~W} / \mathrm{m}^{2}$ (EL1), $29 \%$ at $1 \mathrm{~W} / \mathrm{kg}<\mathrm{SAR} \leq 2 \mathrm{~W} / \mathrm{kg} \mathrm{S}_{\mathrm{ab}}=20 \mathrm{~W} / \mathrm{m}^{2}$ or $\mathrm{S}_{\text {inc }}=10 \mathrm{~W} / \mathrm{m}^{2}$ (EL2), and $32.5 \%$ $\mathrm{SAR}>2 \mathrm{~W} / \mathrm{kg}$ or $\mathrm{S}_{\mathrm{ab}}>20 \mathrm{~W} / \mathrm{m}^{2}$ or $\mathrm{S}_{\mathrm{inc}}>10 \mathrm{~W} / \mathrm{m}^{2}$ (EL3). In most of the experiments (65.1\%) exposure duration was long (ED2, $>1 \mathrm{~h}$ to $\leq 24 \mathrm{~h}$ ), whereas in $21.2 \%$ and $13.7 \%$ they were acute $(\mathrm{ED} 1, \leq 1 \mathrm{~h})$ and chronic $(\mathrm{ED} 3,>24 \mathrm{~h})$, respectively.

\section{Exposure duration (ED)}

\section{Exposure level (EL)}
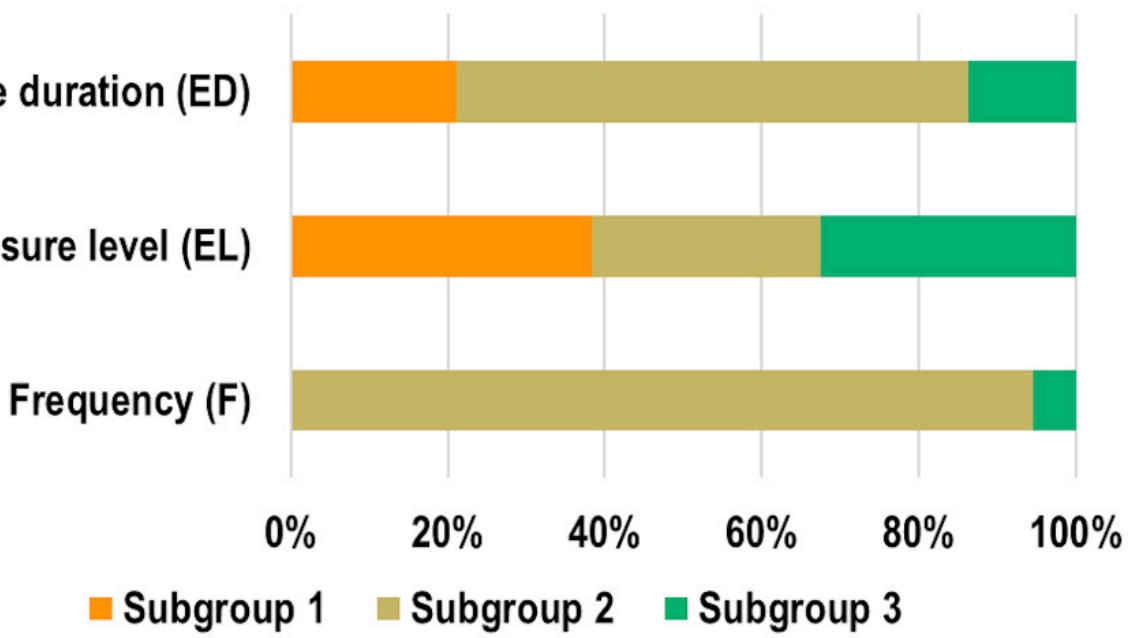

Figure 6. Percentage of experiments belonging to the three subgroups (ED1/ED2/ED3; EL1/EL2/EL3; F1/F2/F3) within the main exposure parameters.

In the majority of experiments $(84.7 \%)$, no statistically significant effects on the analyzed endpoints were found; only the $15.3 \%$ reported statistically significant effects (Figure $7 \mathrm{a})$. The percentage of experiments reporting effects is presented in Figure $7 \mathrm{~b}$ with respect to exposure parameters. The highest incidence occurred in the F3 subgroup, with 13 out of 14 experiments (belonging to two different studies) reporting significant effects. Regarding the exposure level and duration subgroups, the highest incidence was obtained for above limits (EL3, 30.1\%) and acute exposures (ED1, 42.6\%). The incidence of significant and non-significant effects with respect to the analyzed endpoints is shown in Figure 7c. The highest incidence of significant effects was found in terms of MMP modifications (6 out of 12 experiments), followed by caspases activation (7 out of 32 experiments) and the observation of morphological hallmarks (2 out of 10 experiments). For the PE, apoptosis signaling and DNA fragmentation endpoints, the incidence of significant effects ranged from 10.6 to $14.3 \%$ (12 out of 113 experiments for PE; 7 out of 48 for apoptosis signaling; 3 out of 27 experiments for DNA fragmentation). Only two experiments assessed the membrane integrity endpoint and did not find significant effects. Only one experiment assessed expression of cytochrome-c and found a significant alteration. 

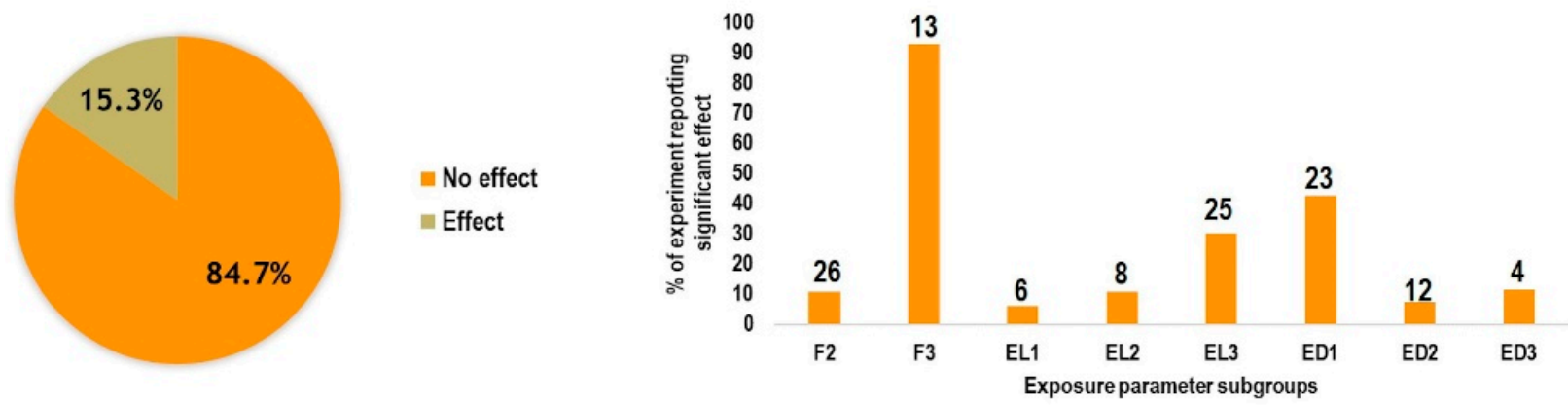

(a)

(b)

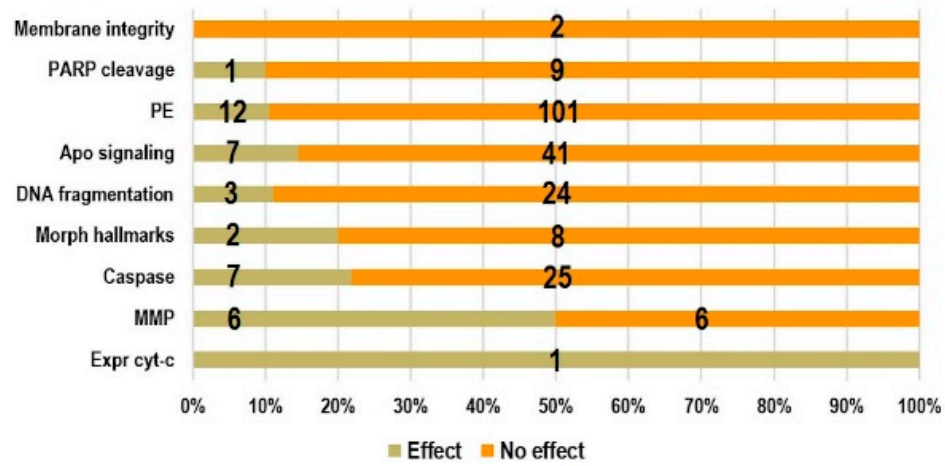

(c)

Figure 7. (a) Percentage of experiments reporting statistically significant effects and of experiments not reporting effects; (b) relative incidence of significant effects in the exposure parameter subgroups (F1 is not reported because no experiments were performed at frequencies below $10 \mathrm{MHz}$; F2/F3; ED1/ED2/ED3; EL1/EL2/EL3 as defined in Table 1; Number above each bar refer to the absolute number of experiments where significant effects were observed); (c) percentage of experiments reporting statistically significant effect or no effect with respect to the endpoints analyzed (numbers on the bars indicate the absolute numbers of experiments performed).

Moreover, the incidence of statistically significant effects in experiments performed with human or animal cells was $13.5 \%$ and $20 \%$, respectively.

Table 3 reports an overview of the studies that did not observe significant alterations of the apoptotic process due to RF-EMF exposures. In 17 out of 31 studies, only one apoptosis endpoint was analyzed; in 20 out of 31 studies the analysis was not performed in blind; and in 7 out of 31 studies positive control was not included. The experiments in which significant alterations of apoptosis endpoints were found belonged to twelve studies, which are overviewed in Table 4 . In 5 out of 11 studies, only one apoptosis endpoint was investigated; in 7 out of 11 studies the analysis was not performed in blind; and in 10 out of 11 studies, positive control was lacking.

\section{Discussion}

\subsection{Summary of Evidence}

One of the main concerns regarding health effects of RF-EMF is that prolonged exposures to weak field levels may cause long-term effects. In spite of the high number of studies published on this matter, the evidence accumulated so far is inconclusive and controversial.

The majority of studies regarding biological effects of RF-EMF are based on an in vitro study design, because this approach is rapid, cost effective, allows exposures to be performed under strictly controlled electromagnetic and environmental conditions and provides insight into mechanistic interactions [1]. Among the biological outcomes that can be of interest for the mechanistic assessment of long-term effects, apoptosis has been increasingly considered over the last twenty years. The gained information has not been 
comprehensively reviewed and does not allow for a complete picture of investigation carried out so far, of the possible effects on this critical cellular process and of the existing gaps in knowledge.

Manna and Gosh reviewed the effects of RF-EMF exposure in cultured mammalian cells on several biological outcomes, including apoptosis. The authors concluded that RF-EMF exposure might affect the apoptotic process in vitro, with results depending on the type of modulation, intermittent mode of exposure and cell model [15]. Halgamuge and co-workers performed an extensive meta-analysis of data from in vitro studies published between 1990 and 2015, and investigating effects of weak RF-EMF from mobile phones. The analysis revealed a lack of uniform responses in any of the investigated outcomes, which included but was not specifically focused on apoptosis, and also highlighted some recurrent patterns of evidence which depended on cell and signal types [14]. Moreover, in the abovementioned reviews, the study inclusion criteria did not take into account the aspects of quality of experimental methods, which have been widely demonstrated to affect the results $[16,17]$. In [16], co-authored by two authors of this review, apoptosis was considered together with proliferation to detect possible statistical associations between RF-EMF exposures and cellular response. Cellular response after exposure to RF-EMF was significantly associated to cell lines rather than to primary cells, but not to other experimental parameters.

In this scoping review, for the first time in our knowledge, we specifically addressed apoptosis outcome in studies evaluating the effects of RF-EMF exposures on mammalian cells in vitro. We conducted a systematic literature review, included studies on the basis of quality criteria defined a priori, and provided an overall picture of what has been published so far.

The systematic literature search yielded a total of 121 relevant papers, but only $34.5 \%$ of them met the inclusion criteria. The majority of retrieved papers failed to comply with quality criteria for good bioelectromagnetic experiments $[16,17,143]$. The main motivations for exclusion were the absence of sham controls and the lack of dosimetry analysis, or of appropriate methods for dosimetry analysis. Lack of compliance with these two criteria indicates that experimental conditions were not identical across study groups, and that there was a low confidence in exposure characterization. Quality of experimental methods has become an issue in bioelectromagnetic research, with the majority of published papers presenting flaws on either electromagnetic or biological requirements, or both. Basic quality criteria for in vitro experiments on RF-EMF exposures include the presence of sham control, dosimetry analysis conducted with standardized methods, temperature control, blind analysis and positive control. The absence of some or all of these requirements has been shown to be highly associated with the detection of effect [16,17]. In this review, we considered three out of five basic requirements as inclusion criteria (sham, dosimetry analysis, temperature control). The motivation of this choice was to include papers with a low risk of bias, but we did not consider the absence of blind analysis and of positive control among the exclusion criteria in order to be more inclusive towards the final analysis of relevant papers. The latter criteria were applied for a deeper characterization of the quality of studies. Indeed, in more than half of the included studies analysis of data was not blinded, and in almost half of the studies positive control was not included in the study design.

It is important mentioning that in more than half of the included studies apoptosis was evaluated by assaying a single endpoint. Since apoptosis occurs via a complex signaling cascade that is tightly regulated at multiple points, and since it presents many features in common with necrosis, it is crucial to perform two or more distinct assays, based on different principles, to confirm that cell death occurred via apoptosis [8]. As an example, the detection of phosphatidylserine externalization requires the use of specific dyes (Annexin- $V$ binds to phosphatidylserine on the plasma membrane, while Propidium Iodide only enters necrotic cells) allowing discrimination of apoptotic from necrotic cells, because an increase 
in membrane permeability is also a feature of necrotic cells. For the same reason, each test must be associated with others based on different apoptotic features.

We have overviewed the main characteristics and outcome of the included studies. The majority of them did not find significant alterations of the apoptotic process due to RFEMF exposure. Looking at the experiments extracted from the studies, when a statistically significant effect was observed it mainly occurred at frequencies above $6 \mathrm{GHz}$, and for acute $(\leq 1 \mathrm{~h})$ exposure durations. However, since the number of studies reporting effects is very small, and the considered experimental conditions are highly heterogeneous, further investigations are needed, together with replication studies, to confirm or confute these results. Moreover, even though the included studies met the basic quality criteria, most of them still presented flaws in the experimental methods (lack of blind analysis and/or positive control, assessment of single endpoints). It can be stated that, to be of value, future studies that investigate the effect of RF-EMF in mammalian cells should aim to be of high methodological quality and be sufficiently powered by performing an adequate number of experiments.

\subsection{Limitations}

The bibliographic search was conducted only on two databases (PubMed and WOS). Even though these two databases may contain the vast majority of studies within the field, it is possible that potentially relevant studies might not be indexed there. Misclassification of studies based on keywords, title or abstract might have also affected the sensitivity of the search strategies. We conducted hand searches to minimize the number of articles missed, but this still may not have captured all eligible articles.

\section{Conclusions}

This scoping review sought to systematically map the research regarding the effects of RF-EMF on apoptosis in mammalian cells, and to identify any existing gaps in knowledge within health risk assessment of RF-EMF exposures. This will definitely facilitate to gain reliable information on the effects of RF exposure on the apoptotic process when in a next step, a quantitative analysis of the papers included in this scoping review will be carried out by mainly addressing questions on the direction of the effect (induction or suppression of apoptosis), effect size, possible dose-response relationship, possible association of the effect size with the quality score of the experiments, and possible major capability of certain exposure parameter ranges to exert an effect. The major gap in knowledge from the qualitative analysis conducted here is the lack of a systematic approach based on quality of the experimental methodologies adopted in the studies retrieved and analyzed in this scoping review.

Therefore, the evidence here presented is a further confirmation that, in spite of the large amount of relevant papers available in the literature, a huge effort still needs to be made in bioelectromagnetic research towards the improvement of experimental quality, which is crucial to guarantee the reliability, robustness and reproducibility of results.

Supplementary Materials: The following supporting information can be downloaded at: https: / /www.mdpi.com/article/10.3390/ijms23042322/s1.

Author Contributions: Conceptualization, S.R., M.R.S., A.S. and O.Z.; methodology, S.R., M.R.S., A.S. and O.Z.; validation, S.R., M.R.S.; formal analysis, S.R., M.R.S., A.S., L.P., O.Z.; investigation, S.R., M.R.S., A.S., O.Z.; resources, S.R., M.R.S., O.Z.; data curation, S.R.; writing-original draft preparation, S.R., M.R.S., O.Z.; writing—review and editing, S.R., M.R.S., A.S., L.P., M.B.L., O.Z.; visualization, S.R., M.R.S., A.S., L.P., M.B.L., O.Z; supervision, M.R.S., O.Z., M.B.L. All authors have read and agreed to the published version of the manuscript.

Funding: This work was partially supported by the Italian Workers' Compensation Authority (INAIL, representative Dr Carlo Grandi), a public, no-profit entity, project “BRiC 2018/06-Scientific evidence on the carcinogenicity of radiofrequency electromagnetic fields"; grant code I85B19000120005. INAIL had no role in the manuscript preparation. 
Data Availability Statement: Not applicable.

Acknowledgments: The authors are thankful to Susanna Lagorio (Istituto Superiore di Sanità, Rome, Italy) for fruitful discussions.

Conflicts of Interest: The authors declare no conflict of interest.

\section{References}

1. IARC. IARC Monographs on the Identification of Carginogenic Hazards to Human-Preamble; International Agency for Research on Cancer: Lyon, France, 2019; p. 41.

2. ICNIRP, ICNIRP guidelines for limiting exposures to electromagnetic fields (100 kHz-300 GHz). Health Phys. 2020, 118, 483-524. [CrossRef] [PubMed]

3. Scientific Committee on Emerging and Newly Identified Health Risks (SCENIHR). Potential Health Effects of Exposure to Electromagnetic Fields (EMF); European Commission: Luxembourg, 2015; p. 288.

4. Kucera, O.; Cifra, M. Radiofrequency and microwave interactions between biomolecular systems. J. Biol. Phys. 2016, 42, 1-8. [CrossRef] [PubMed]

5. Sheppard, A.R.; Swicord, M.L.; Balzano, Q. Quantitative evaluations of mechanisms of radiofrequency interactions with biological molecules and processes. Health Phys. 2008, 95, 365-396. [CrossRef] [PubMed]

6. Burz, C.; Berindan-Neagoe, I.; Balacescu, O.; Irimie, A. Apoptosis in cancer: Key molecular signaling pathways and therapy targets. Acta Oncol. 2009, 48, 811-821. [CrossRef]

7. Singh, R.; Letai, A.; Sarosiek, K. Regulation of apoptosis in health and disease: The balancing act of BCL-2 family proteins. Nat. Rev. Mol. Cell Biol. 2019, 20, 175-193. [CrossRef]

8. Elmore, S. Apoptosis: A review of programmed cell death. Toxicol. Pathol. 2007, 35, 495-516. [CrossRef]

9. Saraste, A. Morphologic criteria and detection of apoptosis. Herz 1999, 24, 189-195. [CrossRef]

10. Saraste, A.; Pulkki, K. Morphologic and biochemical hallmarks of apoptosis. Cardiovasc. Res. 2000, 45, 528-537. [CrossRef]

11. Cherkasova, O.P.; Serdyukova, D.S.; Ratushnyake, A.S.; Nemovaa, E.F.; Kozlovf, E.N.; Shidlovskii, Y.V.; Zaytsev, K.I.; Tuchini, V.V. Effects of Terahertz Radiation on Living Cells: A Review. Biophotonics 2020, 128, 855-866. [CrossRef]

12. Gupta, S.; Sharma, R.S.; Singh, R. Non-ionizing radiation as possible carcinogen. Int. J. Environ. Health Res. 2020, 1-25. [CrossRef]

13. Kocaman, A.; Altun, G.; Kaplan, A.A.; Deniz, O.G.; Yurt, K.K.; Kaplan, S. Genotoxic and carcinogenic effects of non-ionizing electromagnetic fields. Environ. Res. 2018, 163, 71-79. [CrossRef] [PubMed]

14. Halgamuge, M.N.; Skafidas, E.; Davis, D. A meta-analysis of in vitro exposures to weak radiofrequency radiation exposure from mobile phones (1990-2015). Environ. Res. 2020, 184, 109227. [CrossRef] [PubMed]

15. Manna, D.; Ghosh, R. Effect of radiofrequency radiation in cultured mammalian cells: A review. Electromagn. Biol. Med. 2016, 35, 265-301. [CrossRef]

16. Simko, M.; Remondini, D.; Zeni, O.; Scarfi, M.R. Quality Matters: Systematic Analysis of Endpoints Related to "Cellular Life" in Vitro Data of Radiofrequency Electromagnetic Field Exposure. Int. J. Environ. Res. Public Health 2016, 13, 701. [CrossRef] [PubMed]

17. Vijayalaxmi, V.; Foster, K.R. Improving the Quality of Radiofrequency Bioeffects Research: The Need for a Carrot and a Stick. Radiat. Res. 2021, 196, 417-422.

18. McGowan, J.; Straus, S.; Moher, D.; Langlois, E.V.; O’Brien, K.K.; Horsley, T.; Aldcroft, A.; Zarin, W.; Garitty, C.M.; Hempel, S.; et al. Reporting scoping reviews-PRISMA ScR extension. J. Clin. Epidemiol. 2020, 123, 177-179. [CrossRef] [PubMed]

19. Tricco, A.C.; Lillie, E.; Zarin, W.; O’Brien, K.K.; Colquhoun, H.; Levac, D.; Moher, D.; Peters, M.D.J.; Horsley, T.; Weeks, L.; et al. PRISMA Extension for Scoping Reviews (PRISMA-ScR): Checklist and Explanation. Ann. Intern Med. 2018, 169, 467-473. [CrossRef]

20. Romeo, S.; Zeni, O.; Sannino, A.; Lagorio, S.; Biffoni, M.; Scarfi, M.R. Genotoxicity of radiofrequency electromagnetic fields: Protocol for a systematic review of in vitro studies. Environ. Int. 2021, 148, 106386. [CrossRef]

21. Kuster, N.; Schonborn, F. Recommended minimal requirements and development guidelines for exposure setups of bioexperiments addressing the health risk concern of wireless communications. Bioelectromagnetics 2000, 21, 508-514. [CrossRef]

22. Alessio, N.; Santoro, E.; Squillaro, T.; Aprile, D.; Briccola, M.; Giubbini, P.; Marchesani, R.; Muoio, M.R.; Lamberti, M. Low-Level Radiofrequency Exposure Does Not Induce Changes in MSC Biology: An in vitro Study for the Prevention of NIR-Related Damage. Stem Cells Cloning 2019, 12, 49-59. [CrossRef]

23. Al-Serori, H.; Kundi, M.; Ferk, F.; Misik, M.; Nersesyan, A.; Murbach, M.; Lah, T.T.; Knasmuller, S. Evaluation of the potential of mobile phone specific electromagnetic fields (UMTS) to produce micronuclei in human glioblastoma cell lines. Toxicol. In Vitro 2017, 40, 264-271. [CrossRef] [PubMed]

24. Asano, M.; Tanaka, S.; Sakaguchi, M. Effects of normothermic microwave irradiation on CD44(+)/CD24() in breast cancer MDA-MB-231 and MCF-7 cell lines. Biosci. Biotechnol. Biochem. 2020, 84, 103-110. [CrossRef] [PubMed]

25. Asano, M.; Tanaka, S.; Sakaguchi, M.; Matsumura, H.; Yamaguchi, T.; Fujita, Y.; Tabuse, K. Normothermic Microwave Irradiation Induces Death of HL-60 Cells through Heat-Independent Apoptosis. Sci. Rep. 2017, 7, 11406. [CrossRef] [PubMed]

26. Atasoy, A.; Sevim, Y.; Kaya, I.; Yilmaz, M.; Durmus, A.; Sonmez, M.; Omay, S.B.; Ozdemir, F.; Ovali, E. The effects of electromagnetic fields on peripheral blood mononuclear cells in vitro. Bratisl. Lek Listy 2009, 110, 526-529. 
27. Avendaño, C.; Mata, A.; Sanchez Sarmiento, C.A.; Doncel, G.F. Use of laptop computers connected to internet through Wi-Fi decreases human sperm motility and increases sperm DNA fragmentation. Fertil. Steril. 2012, 97, 39-45. [CrossRef]

28. Azma, T.; Nishioka, A.; Ogawa, S.; Nagasaka, H.; Matsumoto, N. Enhanced expression of gene coding for beta-endorphin in human monocytic cells exposed to pulsed radio frequency electric fields through thermal and non-thermal effects. J. Pain Res. 2018, 11, 2887-2896. [CrossRef]

29. Ballardin, M.; Tusa, I.; Fontana, N.; Monorchio, A.; Pelletti, C.; Rogovich, A.; Barale, R.; Scarpato, R. Non-thermal effects of $2.45 \mathrm{GHz}$ microwaves on spindle assembly, mitotic cells and viability of Chinese hamster V-79 cells. Mutat. Res. 2011, 716, 1-9. [CrossRef]

30. Calabro, E.; Condello, S.; Curro, M.; Ferlazzo, N.; Caccamo, D.; Magazu, S.; Ientile, R. Modulation of heat shock protein response in SH-SY5Y by mobile phone microwaves. World J. Biol. Chem. 2012, 3, 34-40. [CrossRef]

31. Cao, Y.; Zhang, W.; Lu, M.X.; Xu, Q.; Meng, Q.Q.; Nie, J.H.; Tong, J. 900-MHz microwave radiation enhances gamma-ray adverse effects on SHG44 cells. J. Toxicol. Environ. Health A 2009, 72, 727-732. [CrossRef]

32. Caraglia, M.; Marra, M.; Mancinelli, F.; D'Ambrosio, G.; Massa, R.; Giordano, A.; Budillon, A.; Abbruzzese, A.; Bismuto, E. Electromagnetic fields at mobile phone frequency induce apoptosis and inactivation of the multi-chaperone complex in human epidermoid cancer cells. J. Cell Physiol. 2005, 204, 539-548. [CrossRef]

33. Cig, B.; Naziroglu, M. Investigation of the effects of distance from sources on apoptosis, oxidative stress and cytosolic calcium accumulation via TRPV1 channels induced by mobile phones and Wi-Fi in breast cancer cells. Biochim. Biophys. Acta 2015, 1848, 2756-2765. [CrossRef] [PubMed]

34. Eghlidospour, M.; Ghanbari, A.; Mortazavi, S.M.J.; Azari, H. Effects of radiofrequency exposure emitted from a GSM mobile phone on proliferation, differentiation, and apoptosis of neural stem cells. Anat. Cell Biol. 2017, 50, 115-123. [CrossRef] [PubMed]

35. Esmekaya, M.A.; Seyhan, N.; Kayhan, H.; Tuysuz, M.Z.; Kursun, A.C.; Yagci, M. Investigation of the effects of 2.1 GHz microwave radiation on mitochondrial membrane potential (DeltaPsim), apoptotic activity and cell viability in human breast fibroblast cells. Cell Biochem. Biophys. 2013, 67, 1371-1378. [CrossRef] [PubMed]

36. Esmekaya, M.A.; Canseven, A.G.; Kayhan, H.; Tuysuz, M.Z.; Sirav, B.; Seyhan, N. Mitochondrial hyperpolarization and cytochrome-c release in microwave-exposed MCF-7 cells. Gen. Physiol. Biophys. 2017, 36, 211-218. [CrossRef]

37. Falzone, N.; Huyser, C.; Franken, D.R.; Leszczynski, D. Mobile phone radiation does not induce pro-apoptosis effects in human spermatozoa. Radiat. Res. 2010, 174, 169-176. [CrossRef]

38. Glazer, E.S.; Zhu, C.; Massey, K.L.; Thompson, C.S.; Kaluarachchi, W.D.; Hamir, A.N.; Curley, S.A. Noninvasive radiofrequency field destruction of pancreatic adenocarcinoma xenografts treated with targeted gold nanoparticles. Clin. Cancer Res. 2010, 16, 5712-5721. [CrossRef]

39. Grasso, R.; Pellitteri, R.; Caravella, S.A.; Musumeci, F.; Raciti, G.; Scordino, A.; Sposito, G.; Triglia, A.; Campisi, A. Dynamic changes in cytoskeleton proteins of olfactory ensheathing cells induced by radiofrequency electromagnetic fields. J. Exp. Biol. 2020, 223, jeb217190. [CrossRef]

40. Harvey, C.; French, P.W. Effects on protein kinase $C$ and gene expression in a human mast cell line, HMC-1, following microwave exposure. Cell Biol. Int. 2000, 23, 739-748. [CrossRef]

41. Hirose, H.; Sakuma, N.; Kaji, N.; Suhara, T.; Sekijima, M.; Nojima, T.; Miyakoshi, J. Phosphorylation and gene expression of p53 are not affected in human cells exposed to $2.1425 \mathrm{GHz}$ band $\mathrm{CW}$ or W-CDMA modulated radiation allocated to mobile radio base stations. Bioelectromagnetics 2006, 27, 494-504. [CrossRef]

42. Jin, Z.; Zong, C.; Jiang, B.; Zhou, Z.; Tong, J.; Cao, Y. The effect of combined exposure of $900 \mathrm{MHz}$ radiofrequency fields and doxorubicin in HL-60 cells. PLoS ONE 2012, 7, e46102. [CrossRef]

43. Jin, H.; Kim, K.; Park, G.Y.; Kim, M.; Lee, H.J.; Jeon, S.; Kim, J.H.; Kim, H.R.; Lim, K.M.; Lee, Y.S. The Protective Effects of EMF-LTE against DNA Double-Strand Break Damage In Vitro and In Vivo. Int. J. Mol. Sci. 2021, 22, 5134. [CrossRef]

44. Jooyan, N.; Goliaei, B.; Bigdeli, B.; Faraji-Dana, R.; Zamani, A.; Entezami, M.; Mortazavi, S.M.J. Direct and indirect effects of exposure to $900 \mathrm{MHz}$ GSM radiofrequency electromagnetic fields on $\mathrm{CHO}$ cell line: Evidence of bystander effect by non-ionizing radiation. Environ Res 2019, 174, 176-187. [CrossRef] [PubMed]

45. Kahya, M.C.; Naziroglu, M.; Cig, B. Selenium reduces mobile phone (900 MHz)-induced oxidative stress, mitochondrial function, and apoptosis in breast cancer cells. Biol. Trace Elem. Res. 2014, 160, 285-293. [CrossRef] [PubMed]

46. Karaca, E.; Durmaz, B.; Aktug, H.; Yildiz, T.; Guducu, C.; Irgi, M.; Koksal, M.G.; Ozkinay, F.; Gunduz, C.; Cogulu, O. The genotoxic effect of radiofrequency waves on mouse brain. J. Neurooncol. 2012, 106, 53-58. [CrossRef] [PubMed]

47. Karkabounas, S.; Havelas, K.; Kostoula, O.K.; Vezyraki, P.; Avdikos, A.; Binolis, J.; Hatziavazis, G.; Metsios, A.; Verginadis, I.; Evangelou, A. Effects of low intensity static electromagnetic radiofrequency fields on leiomyosarcoma and smooth muscle cell lines. Hell J. Nucl. Med. 2006, 9, 167-172.

48. Kayhan, H.; Esmekaya, M.A.; Saglam, A.S.; Tuysuz, M.Z.; Canseven, A.G.; Yagci, A.M.; Seyhan, N. Does MW Radiation Affect Gene Expression, Apoptotic Level, and Cell Cycle Progression of Human SH-SY5Y Neuroblastoma Cells? Cell Biochem. Biophys. 2016, 74, 99-107. [CrossRef] [PubMed]

49. Keczan, E.; Keri, G.; Banhegyi, G.; Stiller, I. Effect of pulsed electromagnetic fields on endoplasmic reticulum stress. J. Physiol. Pharmacol. 2016, 67, 769-775. 
50. Kim, J.H.; Jeon, S.; Choi, H.D.; Lee, J.H.; Bae, J.S.; Kim, N.; Kim, H.G.; Kim, K.B.; Kim, H.R. Exposure to long-term evolution radiofrequency electromagnetic fields decreases neuroblastoma cell proliferation via Akt/mTOR-mediated cellular senescence. $J$. Toxicol. Environ. Health A 2021, 84, 846-857. [CrossRef]

51. Korraah, A.; Odenthal, M.; Kopp, M.; Vigneswaran, N.; Sacks, P.G.; Dienes, H.P.; Stutzer, H.; Niedermeier, W. Induction of apoptosis and up-regulation of cellular proliferation in oral leukoplakia cell lines inside electric field. Oral Surg. Oral Med. Oral Pathol. Oral Radiol. 2012, 113, 644-654. [CrossRef]

52. Koshkina, N.V.; Briggs, K.; Palalon, F.; Curley, S.A. Autophagy and enhanced chemosensitivity in experimental pancreatic cancers induced by noninvasive radiofrequency field treatment. Cancer 2014, 120, 480-491. [CrossRef]

53. Lantow, M.; Viergutz, T.; Weiss, D.G.; Simko, M. Comparative study of cell cycle kinetics and induction of apoptosis or necrosis after exposure of human Mono Mac 6 cells to radiofrequency radiation. Radiat. Res. 2006, 166, 539-543. [CrossRef] [PubMed]

54. Lee, J.S.; Kim, J.Y.; Kim, H.J.; Kim, J.C.; Lee, J.S.; Kim, N.; Park, M.J. Effects of combined radiofrequency field exposure on amyloid-beta-induced cytotoxicity in HT22 mouse hippocampal neurones. J. Radiat. Res. 2016, 57, 620-626. [CrossRef]

55. Lee, S.; Johnson, D.; Dunbar, K.; Dong, H.; Ge, X.; Kim, Y.C.; Wing, C.; Jayathilaka, N.; Emmanuel, N.; Zhou, C.Q.; et al. 2.45 GHz radiofrequency fields alter gene expression in cultured human cells. FEBS Lett. 2005, 579, 4829-4836. [CrossRef] [PubMed]

56. Lee, S.S.; Kim, H.R.; Kim, M.S.; Park, S.; Yoon, E.S.; Park, S.H.; Kim, D.W. Influence of smartphone Wi-Fi signals on adiposederived stem cells. J. Craniofac. Surg. 2014, 25, 1902-1907. [CrossRef] [PubMed]

57. Leszczynski, D.; Joenvaara, S.; Reivinen, J.; Kuokka, R. Non-thermal activation of the hsp27/p38MAPK stress pathway by mobile phone radiation in human endothelial cells: Molecular mechanism for cancer- and blood-brain barrier-related effects. Differentiation 2002, 70, 120-129. [CrossRef]

58. Li, W.H.; Li, Y.Z.; Song, D.D.; Wang, X.R.; Liu, M.; Wu, X.D.; Liu, X.H. Calreticulin protects rat microvascular endothelial cells against microwave radiation-induced injury by attenuating endoplasmic reticulum stress. Microcirculation 2014, $21,506-515$. [CrossRef]

59. Li, X.; Du, M.; Liu, X.; Wu, M.; Ye, H.; Lin, J.; Chen, W.; Wu, G. Millimeter wave treatment inhibits NO-induced apoptosis of chondrocytes through the p38MAPK pathway. Int. J. Mol. Med. 2010, 25, 393-399. [CrossRef]

60. Li, X.; Wu, G.; Wu, M.; Chen, W.; Liu, X. In vitro study of inhibitory millimeter wave treatment effects on the TNF-alpha-induced NF-kappaB signal transduction pathway. Int. J. Mol. Med. 2011, 27, 71-78.

61. Li, X.; Ye, H.; Cai, L.; Yu, F.; Chen, W.; Lin, R.; Zheng, C.; Xu, H.; Ye, J.; Wu, G.; et al. Millimeter wave radiation induces apoptosis via affecting the ratio of Bax/Bcl-2 in SW1353 human chondrosarcoma cells. Oncol. Rep. 2012, 27, 664-672. [CrossRef]

62. Liang, J.; Mok, A.W.; Zhu, Y.; Shi, J. Resonance versus linear responses to alternating electric fields induce mechanistically distinct mammalian cell death. Bioelectrochemistry 2013, 94, 61-68. [CrossRef]

63. Liu, M.L.; Wen, J.Q.; Fan, Y.B. Potential protection of green tea polyphenols against $1800 \mathrm{MHz}$ electromagnetic radiation-induced injury on rat cortical neurons. Neurotox Res. 2011, 20, 270-276. [CrossRef] [PubMed]

64. Liu, Y.X.; Tai, J.L.; Li, G.Q.; Zhang, Z.W.; Xue, J.H.; Liu, H.S.; Zhu, H.; Cheng, J.D.; Liu, Y.L.; Li, A.M.; et al. Exposure to 1950-MHz TD-SCDMA electromagnetic fields affects the apoptosis of astrocytes via caspase-3-dependent pathway. PLoS ONE 2012, 7, e42332. [CrossRef] [PubMed]

65. Liu, Y.X.; Li, G.Q.; Fu, X.P.; Xue, J.H.; Ji, S.P.; Zhang, Z.W.; Zhang, Y.; Li, A.M. Exposure to 3 G mobile phone signals does not affect the biological features of brain tumor cells. BMC Public Health 2015, 15, 764. [CrossRef] [PubMed]

66. Lu, Y.S.; Huang, B.T.; Huang, Y.X. Reactive oxygen species formation and apoptosis in human peripheral blood mononuclear cell induced by $900 \mathrm{MHz}$ mobile phone radiation. Oxid. Med. Cell Longev. 2012, 2012, 740280. [CrossRef]

67. Maioli, M.; Rinaldi, S.; Santaniello, S.; Castagna, A.; Pigliaru, G.; Gualini, S.; Cavallini, C.; Fontani, V.; Ventura, C. Radio electric conveyed fields directly reprogram human dermal skin fibroblasts toward cardiac, neuronal, and skeletal muscle-like lineages. Cell Transplant. 2013, 22, 1227-1235. [CrossRef]

68. Marinelli, F.; La Sala, D.; Cicciotti, G.; Cattini, L.; Trimarchi, C.; Putti, S.; Zamparelli, A.; Giuliani, L.; Tomassetti, G.; Cinti, C. Exposure to $900 \mathrm{MHz}$ electromagnetic field induces an unbalance between pro-apoptotic and pro-survival signals in Tlymphoblastoid leukemia CCRF-CEM cells. J. Cell Physiol. 2004, 198, 324-332. [CrossRef]

69. Martin, D.; Cinca, S.; Margaritescu, I.; Neagu, M.; Iacob, N.; Ighigeanu, D.; Matei, C.; Craciun, G.; Manaila, E.; Chirita, D.A.; et al. Cell investigations simultaneously with exposure to $2.45 \mathrm{GHz}$ microwaves. J. Microw. Power Electromagn. Energy 2009, $43,21-25$. [CrossRef]

70. Mortazavi, S.M.J.; Erfani, N.; Mozdarani, H.; Azmoonfar, R.; Shokrpour, N. Induction of apoptosis by 900 MHz radiofrequency radiation emitted from a GSM mobile phone simulator in bystander Jurkat cells. Int. J. Radiat. Res. 2015, 13, 181-186.

71. Naziroglu, M.; Ozkan, F.F.; Hapil, S.R.; Ghazizadeh, V.; Cig, B. Epilepsy but not mobile phone frequency (900 MHz) induces apoptosis and calcium entry in hippocampus of epileptic rat: Involvement of TRPV1 channels. J. Membr. Biol. 2015, $248,83-91$. [CrossRef]

72. Narvaez, C.J.; Mall, S.K.; Fountain, A.; Parr, B.A.; Chittur, S.V.; Kokorin, B.I.; Botsford, S.F.; Startari, J.F. Specifically Targeted Electromagnetic Fields Arrest Proliferation of Glioblastoma Multiforme U-87 Cells in Culture. Anticancer Res. 2018, 38, 3255-3266. [CrossRef]

73. Nishioka, A.; Kimura, M.; Sakamoto, E.; Nagasaka, H.; Azma, T. Continuous But Not Pulsed Radiofrequency Current Generated by NeuroTherm NT500 Impairs Mitochondrial Membrane Potential in Human Monocytic Cells THP-1. J. Pain Res. 2020, 13, 1763-1768. [CrossRef] [PubMed] 
74. Oh, S.J.; Lee, M.K.; Lee, S.H.; Lee, J.H.; Kim, D.J.; Park, Y.S.; Lee, H.Y. Effect of electromagnetic fields on growth of human cell lines. J. Microbiol. Biotechnol. 2001, 11, 749-755.

75. Ozgur, E.; Guler, G.; Kismali, G.; Seyhan, N. Mobile phone radiation alters proliferation of hepatocarcinoma cells. Cell Biochem. Biophys. 2014, 70, 983-991. [CrossRef] [PubMed]

76. Ozsobaci, N.P.; Ergun, D.D.; Tuncdemir, M.; Ozcelik, D. Protective Effects of Zinc on 2.45 GHz Electromagnetic Radiation-Induced Oxidative Stress and Apoptosis in HEK293 Cells. Biol. Trace Elem. Res. 2020, 194, 368-378. [CrossRef] [PubMed]

77. Pacini, S.; Ruggiero, M.; Sardi, I.; Aterini, S.; Gulisano, F.; Gulisano, M. Exposure to global system for mobile communication (GSM) cellular phone radiofrequency alters gene expression, proliferation, and morphology of human skin fibroblasts. Oncol. Res. 2002, 13, 19-24. [CrossRef]

78. Pastaci Ozsobaci, N.; Duzgun Ergun, D.; Durmus, S.; Tuncdemir, M.; Uzun, H.; Gelisgen, R.; Ozcelik, D. Selenium supplementation ameliorates electromagnetic field-induced oxidative stress in the HEK293 cells. J. Trace Elem. Med. Biol. 2018, 50, 572-579. [CrossRef]

79. Peinnequin, A.; Piriou, A.; Mathieu, J.; Dabouis, V.; Sebbah, C.; Malabiau, R.; Debouzy, J.C. Non-thermal effects of continuous 2.45 GHz microwaves on Fas-induced apoptosis in human Jurkat T-cell line. Bioelectrochemistry 2000, 51, 157-161. [CrossRef]

80. Port, M.; Abend, M.; Romer, B.; Van Beuningen, D. Influence of high-frequency electromagnetic fields on different modes of cell death and gene expression. Int. J. Radiat. Biol. 2003, 79, 701-708. [CrossRef]

81. Radeva, M.; Berg, A.; Berg, H. Induction of Apoptosis and Necrosis in Cancer Cells by Electric Fields, Electromagnetic Fields, and Photodynamically Active Quinoids. Electromagn. Biol. Med. 2009, 23, 185-200. [CrossRef]

82. Solek, P.; Majchrowicz, L.; Bloniarz, D.; Krotoszynska, E.; Koziorowski, M. Pulsed or continuous electromagnetic field induce p53/p21-mediated apoptotic signaling pathway in mouse spermatogenic cells in vitro and thus may affect male fertility. Toxicology 2017, 382, 84-92. [CrossRef]

83. Song, X.L.; Wang, C.H.; Hu, H.Y.; Yu, C.; Bai, C. Microwave induces apoptosis in A549 human lung carcinoma cell line. Chin. Med. J. 2011, 124, 1193-1198. [PubMed]

84. Sueiro-Benavides, R.A.; Leiro-Vidal, J.M.; Salas-Sanchez, A.A.; Rodriguez-Gonzalez, J.A.; Ares-Pena, F.J.; Lopez-Martin, M.E. Radiofrequency at $2.45 \mathrm{GHz}$ increases toxicity, pro-inflammatory and pre-apoptotic activity caused by black carbon in the RAW 264.7 macrophage cell line. Sci. Total Environ. 2021, 765, 142681. [CrossRef] [PubMed]

85. Tomruk, A.; Terzi, Y.K.; Guler, G.O. Assessment of the effects of radiofrequency radiation on human colon epithelium cells. Bratisl. Lek Listy 2019, 120, 299-308. [CrossRef]

86. Urnukhsaikhan, E.; Cho, H.; Mishig-Ochir, T.; Seo, Y.K.; Park, J.K. Pulsed electromagnetic fields promote survival and neuronal differentiation of human BM-MSCs. Life Sci. 2016, 151, 130-138. [CrossRef] [PubMed]

87. Volkova, N.A.; Pavlovich, E.V.; Gapon, A.A.; Nikolov, O.T. Effects of millimeter-wave electromagnetic exposure on the morphology and function of human cryopreserved spermatozoa. Bull. Exp. Biol. Med. 2014, 157, 574-576. [CrossRef] [PubMed]

88. Wu, G.; Sferra, T.; Chen, X.; Chen, Y.; Wu, M.; Xu, H.; Peng, J.; Liu, X. Millimeter wave treatment inhibits the mitochondriondependent apoptosis pathway in chondrocytes. Mol. Med. Rep. 2011, 4, 1001-1006.

89. Wu, H.; Wang, D.; Shu, Z.; Zhou, H.; Zuo, H.; Wang, S.; Li, Y.; Xu, X.; Li, N.; Peng, R. Cytokines produced by microwave-radiated Sertoli cells interfere with spermatogenesis in rat testis. Andrologia 2012, 44 (Suppl. S1), 590-599. [CrossRef]

90. Wu, G.; Chen, X.; Peng, J.; Cai, Q.; Ye, J.; Xu, H.; Zheng, C.; Li, X.; Ye, H.; Liu, X. Millimeter wave treatment induces apoptosis via activation of the mitochondrial-dependent pathway in human osteosarcoma cells. Int. J. Oncol. 2012, 40, $1543-1552$.

91. Xing, F.; Zhan, Q.; He, Y.; Cui, J.; He, S.; Wang, G. 1800 MHz Microwave Induces p53 and p53-Mediated Caspase-3 Activation Leading to Cell Apoptosis In Vitro. PLoS ONE 2016, 11, e0163935. [CrossRef]

92. Yang, L.; Hao, D.; Wang, M.; Zeng, Y.; Wu, S.; Zeng, Y. Cellular neoplastic transformation induced by $916 \mathrm{MHz}$ microwave radiation. Cell. Mol. Neurobiol. 2012, 32, 1039-1046. [CrossRef]

93. Yao, K.; Wu, W.; Yu, Y.; Zeng, Q.; He, J.; Lu, D.; Wang, K. Effect of superposed electromagnetic noise on DNA damage of lens epithelial cells induced by microwave radiation. Investig. Ophthalmol. Vis. Sci. 2008, 49, 2009-2015. [CrossRef] [PubMed]

94. Zhang, Y.; She, F.; Li, L.; Chen, C.; Xu, S.; Luo, X.; Li, M.; He, M.; Yu, Z. p25/CDK5 is partially involved in neuronal injury induced by radiofrequency electromagnetic field exposure. Int. J. Radiat. Biol. 2013, 89, 976-984. [CrossRef] [PubMed]

95. Zhao, T.Y.; Zou, S.P.; Knapp, P.E. Exposure to cell phone radiation up-regulates apoptosis genes in primary cultures of neurons and astrocytes. Neurosci. Lett. 2007, 412, 34-38. [CrossRef] [PubMed]

96. Zhao, L.; Li, J.; Hao, Y.H.; Gao, Y.B.; Wang, S.M.; Zhang, J.; Dong, J.; Zhou, H.M.; Liu, S.C.; Peng, R.Y. Microwave-induced Apoptosis and Cytotoxicity of NK Cells through ERK1/2 Signaling. Biomed. Environ. Sci. 2017, 30, 323-332.

97. Zhijian, C.; Xiaoxue, L.; Wei, Z.; Yezhen, L.; Jianlin, L.; Deqiang, L.; Shijie, C.; Lifen, J.; Jiliang, H. Studying the protein expression in human B lymphoblastoid cells exposed to 1.8-GHz (GSM) radiofrequency radiation (RFR) with protein microarray. Biochem. Biophys. Res. Commun. 2013, 433, 36-39. [CrossRef]

98. Zhou, X.R.; Yuan, H.P.; Qu, W.; Ma, C.Y.; Li, H.Y.; Wang, Y. The study of retinal ganglion cell apoptosis induced by different intensities of microwave irradiation. Ophthalmologica 2008, 222, 6-10. [CrossRef]

99. Zhu, W.; Zhang, W.; Wang, H.; Xu, J.; Li, Y.; Lv, S. Apoptosis induced by microwave radiation in pancreatic cancer JF305 cells. Can. J. Physiol. Pharmacol. 2014, 92, 324-329. [CrossRef] 
100. Zuo, H.; Lin, T.; Wang, D.; Peng, R.; Wang, S.; Gao, Y.; Xu, X.; Zhao, L.; Wang, S.; Su, Z. RKIP Regulates Neural Cell Apoptosis Induced by Exposure to Microwave Radiation Partly Through the MEK/ERK/CREB Pathway. Mol. Neurobiol. 2015, 51, 1520-1529. [CrossRef]

101. Belyaev, I.Y.; Hillert, L.; Protopopova, M.; Tamm, C.; Malmgren, L.O.; Persson, B.R.; Selivanova, G.; Harms-Ringdahl, M. 915 MHz microwaves and $50 \mathrm{~Hz}$ magnetic field affect chromatin conformation and 53BP1 foci in human lymphocytes from hypersensitive and healthy persons. Bioelectromagnetics 2005, 26, 173-184. [CrossRef]

102. Bourthoumieu, S.; Magnaudeix, A.; Terro, F.; Leveque, P.; Collin, A.; Yardin, C. Study of p53 expression and post-transcriptional modifications after GSM-900 radiofrequency exposure of human amniotic cells. Bioelectromagnetics 2013, 34, 52-60. [CrossRef]

103. Capri, M.; Scarcella, E.; Bianchi, E.; Fumelli, C.; Mesirca, P.; Agostini, C.; Remondini, D.; Schuderer, J.; Kuster, N.; Franceschi, C.; et al. $1800 \mathrm{MHz}$ radiofrequency (mobile phones, different Global System for Mobile communication modulations) does not affect apoptosis and heat shock protein 70 level in peripheral blood mononuclear cells from young and old donors. Int. J. Radiat. Biol. 2004, 80, 389-397. [CrossRef] [PubMed]

104. Capri, M.; Scarcella, E.; Fumelli, C.; Bianchi, E.; Salvioli, S.; Mesirca, P.; Agostini, C.; Antolini, A.; Schiavoni, A.; Castellani, G.; et al. In vitro exposure of human lymphocytes to $900 \mathrm{MHz}$ CW and GSM modulated radiofrequency: Studies of proliferation, apoptosis and mitochondrial membrane potential. Radiat. Res. 2004, 162, 211-218. [CrossRef] [PubMed]

105. Chauhan, V.; Mariampillai, A.; Kutzner, B.C.; Wilkins, R.C.; Ferrarotto, C.; Bellier, P.V.; Marro, L.; Gajda, G.B.; Lemay, E.; Thansandote, A.; et al. Evaluating the biological effects of intermittent 1.9 GHz pulse-modulated radiofrequency fields in a series of human-derived cell lines. Radiat. Res. 2007, 167, 87-93. [CrossRef] [PubMed]

106. Chen, C.; Ma, Q.; Liu, C.; Deng, P.; Zhu, G.; Zhang, L.; He, M.; Lu, Y.; Duan, W.; Pei, L.; et al. Exposure to 1800 MHz radiofrequency radiation impairs neurite outgrowth of embryonic neural stem cells. Sci. Rep. 2014, 4, 5103. [CrossRef] [PubMed]

107. Choi, J.; Min, K.; Jeon, S.; Kim, N.; Pack, J.K.; Song, K. Continuous Exposure to 1.7 GHz LTE Electromagnetic Fields Increases Intracellular Reactive Oxygen Species to Decrease Human Cell Proliferation and Induce Senescence. Sci. Rep. 2020, 10, 9238. [CrossRef]

108. De Amicis, A.; Sanctis, S.D.; Cristofaro, S.D.; Franchini, V.; Lista, F.; Regalbuto, E.; Giovenale, E.; Gallerano, G.P.; Nenzi, P.; Bei, R.; et al. Biological effects of in vitro THz radiation exposure in human foetal fibroblasts. Mutat. Res. Genet. Toxicol. Environ. Mutagen. 2015, 793, 150-160. [CrossRef]

109. Durdik, M.; Kosik, P.; Markova, E.; Somsedikova, A.; Gajdosechova, B.; Nikitina, E.; Horvathova, E.; Kozics, K.; Davis, D.; Belyaev, I. Microwaves from mobile phone induce reactive oxygen species but not DNA damage, preleukemic fusion genes and apoptosis in hematopoietic stem/progenitor cells. Sci. Rep. 2019, 9, 16182. [CrossRef]

110. Glaser, K.; Rohland, M.; Kleine-Ostmann, T.; Schrader, T.; Stopper, H.; Hintzsche, H. Effect of Radiofrequency Radiation on Human Hematopoietic Stem Cells. Radiat. Res. 2016, 186, 455-465. [CrossRef]

111. Gulati, S.; Kosik, P.; Durdik, M.; Skorvaga, M.; Jakl, L.; Markova, E.; Belyaev, I. Effects of different mobile phone UMTS signals on DNA, apoptosis and oxidative stress in human lymphocytes. Environ. Pollut. 2020, 267, 115632. [CrossRef]

112. Gurisik, E.; Warton, K.; Martin, D.K.; Valenzuela, S.M. An in vitro study of the effects of exposure to a GSM signal in two human cell lines: Monocytic U937 and neuroblastoma SK-N-SH. Cell Biol. Int. 2006, 30, 793-799. [CrossRef]

113. Hook, G.J.; Zhang, P.; Lagroye, I.; Li, L.; Higashikubo, R.; Moros, E.G.; Straube, W.L.; Pickard, W.F.; Baty, J.D.; Roti Roti, J.L. Measurement of DNA damage and apoptosis in Molt-4 cells after in vitro exposure to radiofrequency radiation. Radiat. Res. 2004, 161, 193-200. [CrossRef] [PubMed]

114. Hoyto, A.; Luukkonen, J.; Juutilainen, J.; Naarala, J. Proliferation, oxidative stress and cell death in cells exposed to $872 \mathrm{MHz}$ radiofrequency radiation and oxidants. Radiat. Res. 2008, 170, 235-243. [CrossRef] [PubMed]

115. Hoyto, A.; Sokura, M.; Juutilainen, J.; Naarala, J. Radiofrequency radiation does not significantly affect ornithine decarboxylase activity, proliferation, or caspase-3 activity of fibroblasts in different physiological conditions. Int. J. Radiat. Biol. 2008, 84, 727-733. [CrossRef] [PubMed]

116. Joubert, V.; Bourthoumieu, S.; Leveque, P.; Yardin, C. Apoptosis is induced by radiofrequency fields through the caspaseindependent mitochondrial pathway in cortical neurons. Radiat. Res. 2008, 169, 38-45. [CrossRef]

117. Joubert, V.; Leveque, P.; Cueille, M.; Bourthoumieu, S.; Yardin, C. No apoptosis is induced in rat cortical neurons exposed to GSM phone fields. Bioelectromagnetics 2007, 28, 115-121. [CrossRef]

118. Lin, Y.Y.; Wu, T.; Liu, J.Y.; Gao, P.; Li, K.C.; Guo, Q.Y.; Yuan, M.; Lang, H.Y.; Zeng, L.H.; Guo, G.Z. 1950 MHz Radio Frequency Electromagnetic Radiation Inhibits Testosterone Secretion of Mouse Leydig Cells. Int. J. Environ. Res. Public Health 2017, 15, 17. [CrossRef]

119. Liu, K.; Zhang, G.; Wang, Z.; Liu, Y.; Dong, J.; Dong, X.; Liu, J.; Cao, J.; Ao, L.; Zhang, S. The protective effect of autophagy on mouse spermatocyte derived cells exposure to $1800 \mathrm{MHz}$ radiofrequency electromagnetic radiation. Toxicol. Lett. 2014, 228, 216-224. [CrossRef]

120. Merola, P.; Marino, C.; Lovisolo, G.A.; Pinto, R.; Laconi, C.; Negroni, A. Proliferation and apoptosis in a neuroblastoma cell line exposed to $900 \mathrm{MHz}$ modulated radiofrequency field. Bioelectromagnetics 2006, 27, 164-171. [CrossRef]

121. Moquet, J.; Ainsbury, E.; Bouffler, S.; Lloyd, D. Exposure to low level GSM 935 MHZ radiofrequency fields does not induce apoptosis in proliferating or differentiated murine neuroblastoma cells. Radiat. Prot. Dosimetry 2008, 131, 287-296. [CrossRef] 
122. Palumbo, R.; Brescia, F.; Capasso, D.; Sannino, A.; Sarti, M.; Capri, M.; Grassilli, E.; Scarfi, M.R. Exposure to 900 MHz radiofrequency radiation induces caspase 3 activation in proliferating human lymphocytes. Radiat. Res. 2008, 170, 327-334. [CrossRef]

123. Sanchez, S.; Haro, E.; Ruffie, G.; Veyret, B.; Lagroye, I. In vitro study of the stress response of human skin cells to GSM-1800 mobile phone signals compared to UVB radiation and heat shock. Radiat. Res. 2007, 167, 572-580. [CrossRef] [PubMed]

124. Sanchez, S.; Milochau, A.; Ruffie, G.; Poulletier de Gannes, F.; Lagroye, I.; Haro, E.; Surleve-Bazeille, J.E.; Billaudel, B.; Lassegues, M.; Veyret, B. Human skin cell stress response to GSM-900 mobile phone signals. In vitro study on isolated primary cells and reconstructed epidermis. FEBS J. 2006, 273, 5491-5507. [CrossRef] [PubMed]

125. Simon, D.; Daubos, A.; Pain, C.; Fitoussi, R.; Vie, K.; Taieb, A.; de Benetti, L.; Cario-Andre, M. Exposure to acute electromagnetic radiation of mobile phone exposure range alters transiently skin homeostasis of a model of pigmented reconstructed epidermis. Int. J. Cosmet Sci. 2013, 35, 27-34. [CrossRef] [PubMed]

126. Terro, F.; Magnaudeix, A.; Crochetet, M.; Martin, L.; Bourthoumieu, S.; Wilson, C.M.; Yardin, C.; Leveque, P. GSM-900 MHz at low dose temperature-dependently downregulates alpha-synuclein in cultured cerebral cells independently of chaperone-mediatedautophagy. Toxicology 2012, 292, 136-144. [CrossRef] [PubMed]

127. Wang, C.; Wang, X.; Zhou, H.; Dong, G.; Guan, X.; Wang, L.; Xu, X.; Wang, S.; Chen, P.; Peng, R.; et al. Effects of pulsed 2.856 GHz microwave exposure on BM-MSCs isolated from C57BL/6 mice. PLoS ONE 2015, 10, e0117550. [CrossRef] [PubMed]

128. Zeni, O.; Sannino, A.; Sarti, M.; Romeo, S.; Massa, R.; Scarfi, M.R. Radiofrequency radiation at 1950 MHz (UMTS) does not affect key cellular endpoints in neuron-like PC12 cells. Bioelectromagnetics 2012, 33, 497-507. [CrossRef]

129. Zhang, K.Y.; Xu, H.; Du, L.; Xing, J.L.; Zhang, B.; Bai, Q.S.; Xu, Y.Q.; Zhou, Y.C.; Zhang, J.P.; Zhou, Y.; et al. Enhancement of X-ray Induced Apoptosis by Mobile Phone-Like Radio-Frequency Electromagnetic Fields in Mouse Spermatocyte-Derived Cells. Int. J. Environ. Res. Public Health 2017, 14, 616. [CrossRef]

130. Zhou, H.; Dong, G.; Zheng, W.; Wang, S.; Wang, L.; Zhi, W.; Wang, C. Radiofrequency radiation at $2.856 \mathrm{GHz}$ does not affect key cellular endpoints in neuron-like PC12 cells. Electromagn. Biol. Med. 2019, 38, 102-110. [CrossRef]

131. Zielinski, J.; Ducray, A.D.; Moeller, A.M.; Murbach, M.; Kuster, N.; Mevissen, M. Effects of pulse-modulated radiofrequency magnetic field (RF-EMF) exposure on apoptosis, autophagy, oxidative stress and electron chain transport function in human neuroblastoma and murine microglial cells. Toxicol. In Vitro 2020, 68, 104963. [CrossRef]

132. Borovkova, M.; Serebriakova, M.; Fedorov, V.; Sedykh, E.; Vaks, V.; Lichutin, A.; Salnikova, A.; Khodzitsky, M. Investigation of terahertz radiation influence on rat glial cells. Biomed. Opt. Express 2017, 8, 273-280. [CrossRef]

133. Buttiglione, M.; Roca, L.; Montemurno, E.; Vitiello, F.; Capozzi, V.; Cibelli, G. Radiofrequency radiation (900 MHz) induces Egr-1 gene expression and affects cell-cycle control in human neuroblastoma cells. J. Cell Physiol. 2007, 213, 759-767. [CrossRef] [PubMed]

134. Canseven, A.G.; Esmekaya, M.A.; Kayhan, H.; Tuysuz, M.Z.; Seyhan, N. Effects of microwave exposure and Gemcitabine treatment on apoptotic activity in Burkitt's lymphoma (Raji) cells. Electromagn. Biol. Med. 2015, 34, 322-326. [CrossRef] [PubMed]

135. Hou, Q.; Wang, M.; Wu, S.; Ma, X.; An, G.; Liu, H.; Xie, F. Oxidative changes and apoptosis induced by 1800-MHz electromagnetic radiation in NIH/3T3 cells. Electromagn. Biol. Med. 2015, 34, 85-92. [CrossRef] [PubMed]

136. Joubert, V.; Leveque, P.; Rametti, A.; Collin, A.; Bourthoumieu, S.; Yardin, C. Microwave exposure of neuronal cells in vitro: Study of apoptosis. Int. J. Radiat. Biol. 2006, 82, 267-275. [CrossRef]

137. Li, D.Y.; Song, J.D.; Liang, Z.Y.; Oskouei, K.; Xiao, X.Q.; Hou, W.Z.; Li, J.T.; Yang, Y.S.; Wang, M.L.; Murbach, M. Apoptotic Effect of $1800 \mathrm{MHz}$ Electromagnetic Radiation on NIH/3T3 Cells. Int. J. Environ. Res. Public Health 2020, 17, 819. [CrossRef]

138. Nikolova, T.; Czyz, J.; Rolletschek, A.; Blyszczuk, P.; Fuchs, J.; Jovtchev, G.; Schuderer, J.; Kuster, N.; Wobus, A.M. Electromagnetic fields affect transcript levels of apoptosis-related genes in embryonic stem cell-derived neural progenitor cells. FASEB J. 2005, 19, 1686-1688. [CrossRef]

139. Sefidbakht, Y.; Moosavi-Movahedi, A.A.; Hosseinkhani, S.; Khodagholi, F.; Torkzadeh-Mahani, M.; Foolad, F.; Faraji-Dana, R. Effects of $940 \mathrm{MHz}$ EMF on bioluminescence and oxidative response of stable luciferase producing HEK cells. Photochem. Photobiol. Sci. 2014, 13, 1082-1092. [CrossRef]

140. Yoon, S.Y.; Kim, K.T.; Jo, S.J.; Cho, A.R.; Jeon, S.I.; Choi, H.D.; Kim, K.H.; Park, G.S.; Pack, J.K.; Kwon, O.S.; et al. Induction of hair growth by insulin-like growth factor-1 in $1763 \mathrm{MHz}$ radiofrequency-irradiated hair follicle cells. PLoS ONE 2011, 6, e28474 [CrossRef]

141. Zhao, R.; Liu, Y.; Liu, S.; Luo, T.; Zhong, G.Y.; Liu, A.; Zeng, Q.; Xin, S.X. Apoptosis-Promoting Effects on A375 Human Melanoma Cells Induced by Exposure to 35.2-GHz Millimeter Wave. Technol. Cancer Res. Treat. 2020, 19, 1533033820934131. [CrossRef]

142. Zuo, H.; Lin, T.; Wang, D.; Peng, R.; Wang, S.; Gao, Y.; Xu, X.; Li, Y.; Wang, S.; Zhao, L.; et al. Neural cell apoptosis induced by microwave exposure through mitochondria-dependent caspase-3 pathway. Int. J. Med. Sci. 2014, 11, 426-435. [CrossRef]

143. Zeni, O.; Scarfi, M.R. Experimental requirements for in vitro studies aimed to evaluate the biological effects of radiofrequency radiation. In Microwave Materials Characterization; Costanzo, S., Ed.; InTech: Rijeka, Croatia, 2012. 